A major purpose of the Technical Information Center is to provide the broadest dissemination possible of information contained in DOE's Research and Development Reports to business, industry, the academic community, and federal, state and local governments.

Although a small portion of this report is not reproducible, it is being made available to expedite the availability of information on the research discussed herein. 
This report was prepared as an account of work sponsored by an agency of the United State: Government. Neither the United States Government nor any agency thereof, nor any of their employees, makes any warranty. express or implied, or assumes any legal liability or responsibility for the acsuracy, completeness, or usefulness c! any information, apparatus, produc:, or process disclosed, or represents that its use would not infringe privately owned rights. Reference herein to any specific commercial prudect, process, or servicr by trade name, trademart. manufacturer. of otherwiec does not necessarily constituie or imply its endorsement, recommendation, or favosing by the United Siates Government or iny agency thereof. The views and opiniuns of authors expressed herein do not necessarily state or reflect those of the United States Government or any agency thereof.
OIMIL/CSD/Ti- -213

\section{DE84 017646}

Consolitinted Fud Reprocessing Program

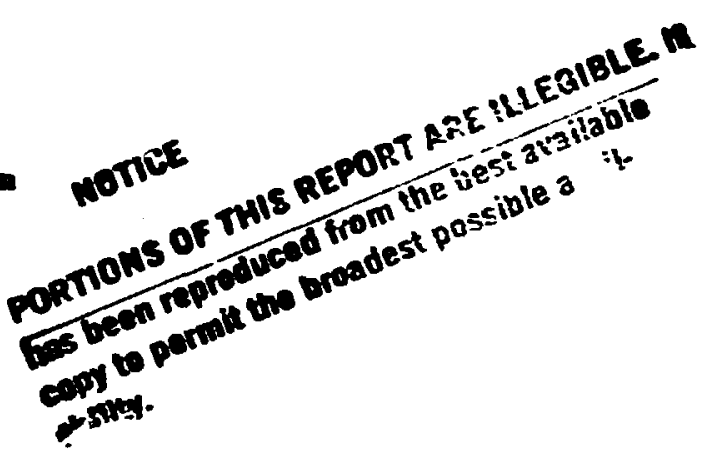

\title{
PHYSICS CONSIDERATIONS INVOLVED IN THE USE OF INSOLUBLE POISONS AS AN ALTERNATE MEANS OF ENSURING SUBCRITICALITY IN THE ROTARY FUEL DISSOLVER
}

\author{
J. A. Buctroiz \\ CCMPUTER SERVICES
}

\author{
Manuscript Completed: October 1983 \\ Date Published: Aeguat 1984
}

\begin{abstract}
NOTICE This document contains informar. $n$ of a preliminary nature. it is subject to revision or correction and therefore does nct represent a final report
\end{abstract}

\author{
Prepared by the \\ Oak Ridge National Laboratory \\ Oak Riuge, Tennescee 37831 \\ operated by \\ Martin Marietta Energy Systems, Inc. \\ for the \\ U.S. DEPARTMENT OF ENERGY \\ under Contruet No. DE-AC05-840R21400
}
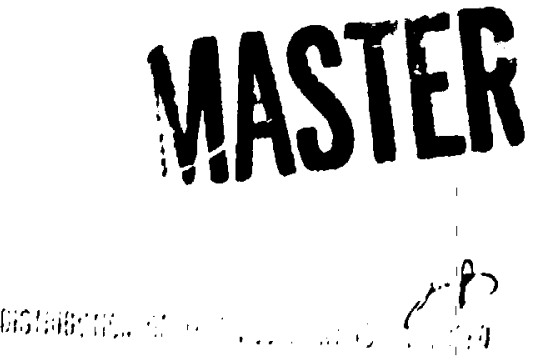


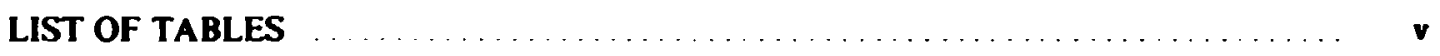

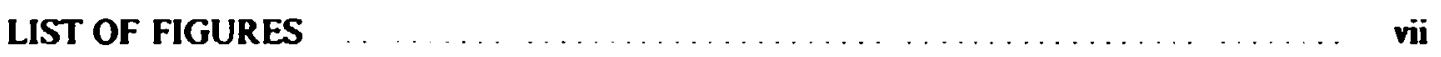

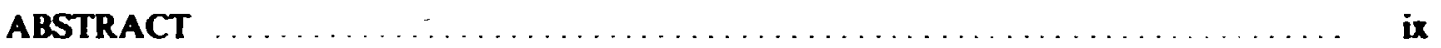

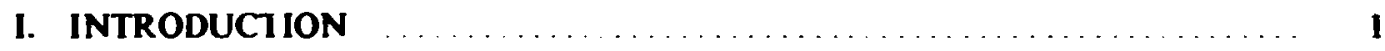

II. INITIAL CRITICALITY SCOPIIVG STUDIES FOR HOMOGENEOUS

III. EFFECT OF ADDITICNAL MODERATION ON THREE HOMOGENEOUS

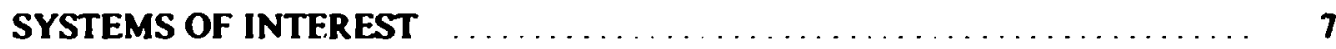

IV. EFFECT OF SPATIAL-SELF-SHIELDING IN LARGE B_C PELLETS FOR SEVERAL DIFFERENT SYSTEMS $\ldots \ldots \ldots \ldots \ldots \ldots \ldots \ldots \ldots \ldots \ldots \ldots$ II

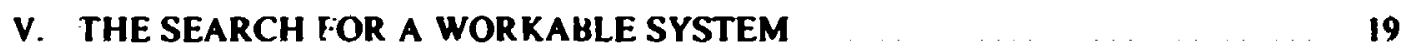

V.A. RESTRICTIONS ON THE SIZE AND COMPOSITION OF THE STEEL-CLAD B_C PELLETS

V.B. DETERMINING LIMITS ON THE RELATIVE AMOUNT OF FUEL ALLOWED IN THE SYSTEM $\ldots \ldots \ldots \ldots \ldots \ldots \ldots \ldots \ldots \ldots .20$

V.C. A PHYSICAL INTERPRETATION OF THE CALCULATIONAL MODEL

VI. MULTIDIMENSIONAL ANALYSIS, INCLUDING RESONANCE-SELFSHIELDING EFFECTS IN THE FUEL LUMP(S) AND SPATIAL-SELFSHIELDING EFFECTS IN THE B,C PELLET(S)

VI.A. DESCRIPTION OF THE THREE-DIMENSIONAL CALCULATIONAL MODEL AND THE NECESSARY MODIFICATIONS TO KENO-IV . . 27

VI.B. CRITERIA FOR SELECTING FUEL LUMP SIZES TO BE STUDIED ... 29

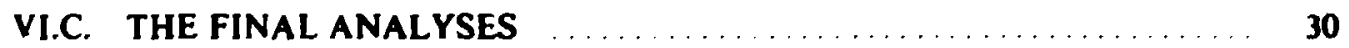

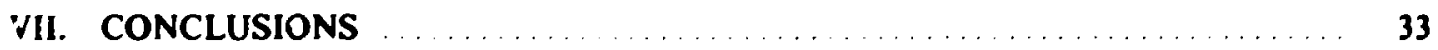

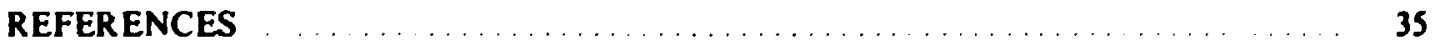

APPENDICES

A. AUTOMATED PROCEDURE USED FOR GENERATING THE ACTUAL CSASI INPUT FOR THE CALCULATIONS DESCRIBED IN SECTION II

B. AUTOMATED PKOCEDIJRE USED FOR GENERATING THE ACTUAL CSASI INPUT FOR THE CALCULATIONS DESCRIBED IN SECTION III

C. AUT̃OMATED PROCEDURE USED FOR GENERATING THE ACTUAL CSASI INPUT FOR THE CALCULATIONS DESCRIBED IN SECTIONS IV AND V.B

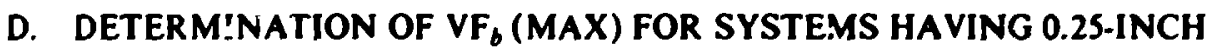
DIP.METER, STEEL-CLAD B,C PELLETS

E. AUTOMATED PROCEDURE USED FOR GFNEI:ATING THE ACTUAL CSAS2 INPUT FOR THE CALCULATIONS DESCRIBED IN SECTION VI.C 


\section{LST OF TABLES}

Table 1. Nuclide Concentrations for the Basic Materials Used in This Study

Table 2. Neutron Multiplication Factor $\left(k_{\infty 0}\right)$ for Infinite Homogeneous Mixtures of $\mathrm{MO}_{2}, \mathrm{~B}_{4} \mathrm{C}$ and SS-316

Table 3. Neutron Mu!tiplication Factor $\left(k_{x}\right)$ as a Function of the $H / P u$ Ratio for Several Infinite Homogeneous Mirtures of $\mathrm{MO}_{2}, \mathrm{H}_{2} \mathrm{O}, \mathrm{B}_{4} \mathrm{C}$, ind SS-316

Table 4. Neutron Multiplization Factor $\left(k_{2}\right)$ as a Function of the $H / P u$ Ratio for Several Systems in Which 0.5-inch-Diameter Steel-Clad BA C Pellets are Uniformly Dispersed in a Homogeneous Mixture of Fuel and Watcr

Table 5. Neutron Multiplication Factor $\left(k_{x}\right)$ as a Function of the H/Pu Ratio Several Other Systens in Which 0.5-inct-Diameter Steel-Clad B4C Pelkets are Uniformly Dispersed in a Homogeneous Mixture of Fuel and Water

Table 6. Neutron Multiplication Factor $\left(k_{\infty}\right)$ as a Function of the $H / P u$ Ratio for Several Systems in Which 0.25-inch-Diametir Steel-Clad B4C Pellets are Uniformly Dispersed in a Homogeneous Mixture of Fuel and Water

Table 7. Neutron Multiplication Factor $\left(k_{\infty}\right)$ as a Function of the H/Pu Ratio for a Safely Subcritical System in Which 0.25-inch-Diameter Steel-Clad B,C Pellets are Uniformly Dispersed in a Homogeneous Mixture ci Fuel and Water $\left(V F_{f}=0.34, V F_{b}=0.50\right)$

Table 8. Neutron Multiplication Factor $\left(k_{\infty}\right)$ as a Function of the $H ; \vec{F}:$ Ratio for Several Systems in Which 0.25-inch-Diameter Steel-Clad B,C Pellets are Uniformly Dispersed in a Slurry ui Water Containing Discrete Fuei Lumps of a Particular Diameter $\left(D_{f}=1.00 \mathrm{~cm}, 0.67 \mathrm{~cm}, 0.33 \mathrm{~cm}, 0.10 \mathrm{~cm}\right.$, and $\left.0.01 \mathrm{~cm}\right)$

Table 9. Actual Thickness of the Stainless-Steel Cladding on the $B_{4} C$ Pellet as a Function of $\mathbf{V F}_{\mathbf{f}}$ and $\mathbf{V F _ { b }}$. 


\section{LIST OF FIGURWS}

Page

Fig. 1. Neutror Multiplication Factor $\left(k_{\infty}\right)$ as a Function of the $H / P u$ Ratio fer Several Infinite Homogeneous Mixtures of $\mathrm{MO}_{2}, \mathrm{H}_{2} \mathrm{O}, \mathrm{B}_{4} \mathrm{C}$, and SS-316.

Fig. 2. Neutron Multiplication Factor $\left(\mathrm{L}_{\infty}\right)$ as a Function of the $H / P u$ Ratio for One System in Which 0.5-inch-Diameter Steel-Clad B4C Pellets are Uniformly Dispersed in a Homogenized Mixture of Fuel and Water $\left(V F_{f}=0.60, V F_{b}=0.95\right)$

Fig. 3a. Neutron Multiplication Factor $\left(k_{\infty}\right)$ as a Function of the $H / P u$ Ratio for Two Different Systems in Which 0.5-inch-Diameter Steel-Clad B4C Pellets are Uniformly Dispersed in a Homogenized Mixture of Fuel and Water $\left(V_{f}=0.30\right.$, $\mathrm{VF}_{\mathrm{b}}=0.15$ and $\mathrm{VF}_{\mathrm{b}}=0.95$ )

Fig. 3b. Neurron Multiplication Factor ( $k_{\infty}$ ) as a Function of the H/Pu Ratio for Two Different Sys:ems in Which 0.5-inch-Diameter Steel-Clad $B_{4} C$ Pellets are Uniformly Dispersed in a Homogenized Mixture of Fuel and Water $\left(V_{f}=0.49 ; F_{b}=0.50\right.$ and $V F_{b}=0.95$ )

Fig. 4. Neutron Multiplication Factor $\left(k_{\infty}\right)$ as a Function of the $H / P u$ Ratio for Several Systems in Which 0.25-inch-Diametei Steel-Clad $\mathrm{B}_{4} \mathrm{C}$ Pellets are Uniformly Dispersed in a Homogenized Mixture of Fuel and Water

Fig. 5. Neutron Multiplication Factor $\left(k_{\infty}\right)$ as a Function of the H/Pu Ratio for a Safely Subcritical System in Which 0.25-inch-Diameter Steel-Clad B4 C Pellets are Uniformly Dispersed in a Homogenized Mixturc of Fuel and Water $\left(V F_{r}=0.34\right.$, $V F_{b}=0.50$ )

Fig. 6. Neutron Multiplication Factor $\left(k_{\infty}\right)$ as a Function $\because:$ the $H / P u$ Ratio for Several Systems in Which 0.25-inch-Diameter Steel-Clad BaC Pellets are Uniformly Dispersed in a Slurry of Water Containing Discrete Fuel Lumps of a Particular Diameter $\left(D_{f}=1.00 \mathrm{~cm}, 0.67 \mathrm{~cm}, 0.33 \mathrm{~cm}, 0.10 \mathrm{~cm}\right.$, and $\left.0.01 \mathrm{~cm}\right)$ 


\begin{abstract}
ALSTRACT
While the use of soluble neutron poisons coupled with mass control is sufficient to guarantee subcriticality in the rotary fuel dissolver, an alternate means of ensuring subcriticality was also investigated from a reactor physics viewpoint. The scheme proposed in this report relies on the use of 0.25-inch-diameter stainkess-steel-clad $B_{4} C$ pellets which could be mixed uniformly with the sheared fuel from the Fast Flux Test Facility (FFTr) as it is being fod to the dissolver. The cakculations described herein show that an infinite system of the type just described would be safely subcritical $\left(k_{\infty} \leqslant 0.95\right)$ at all $\mathrm{H} / \mathrm{Pu}$ ratios as long as the relative volume of FFTF fuel in the dry system does not exceed 34\%. The operational complexities and equipmeal modifications necessary to employ this method of criticality control have not been examined.
\end{abstract}




\section{INTRODUCTION}

The rotary fuel dissolver may be described as a large (30-inch diameter) drum which rotates about a near-horizontal axis. Axially it is divided into several stages. Sheared segments of FFTF fued elements (1 to 2 inches long $\times 0.5 \mathrm{~cm}$ diameter) are dropped in the first stage, with the partially dissolved fuel stowly advancing to the last stage where the emply cladding hulls are ultimately removed. At the same time, a nitric acid solution is flowing through the dissolver in a counter-current direction. That is: the nitric acid solution enters through the last stage where in essentially rinses the empty hulks, and flows down toward the first stage where the dissolved fuel in solution is carried out of the dissolver with the effluent. Because of this counter-current flow through the dissolver, the H/Pu ratio may be quite high in cleaner stages where the solution enters, and relatively low in the frrat stages where the undissolved fuel enters. Periodically, of course, the dissolver is rotated one fu'l revolution in the backwards direction so as to advance the fuel from one stage to the next. When this happens, the fuel is "scooped up" out of the solution, and the H/Pu ratio effectively goes to zero.

To ensure subcriticality in the well-moderated region, trace amounts of a strong thermal absorber are added to the nitric acid solution. Typically, -5 grams of gadolinium per liter of solution is sufficient. For drier systems, however, the amount of soluble poison present would not be effective, and mass control has been proposed as the primary mezns of ensuring subscriticality. Since either the loss of mass control in the dry system or the loss of gadolinium in the wet sysi=m could lead to a criticality incident, these combined controls may still be viewed as a "single contingency" approach. Hence, a study was initiated to investigate the use of another, independent means of ensuring subcriticality under all conditions.

The purpose of this report is to show that roperly-sized stainless-steel-clad $B_{4} C$ pellets uniformly mixed with the sheared fuel can provide an independent means of ensuring subcriticality under all conditions. Indeed, since there are nonobvious restrictions on the size of the $\mathrm{B}_{4} C_{\text {pellets }}$ that can be used in this particular application, the report will attempt to present and explain in a more-or-less chronological order the various physics considerations that led to the dimensions finally proposed.

All of the calculations described in this report were performed using the CSASI or CSAS2 criticality safet; analysis modules of the SCALE system. ${ }^{1.2}$ This modular code system was sponsored by the NRC and developed at ORNL for Standardized Computer Analyses for Licensing Evaluation. In each case, the SCALE system's 27-group ENDF-IV cross-section library was used. 


\section{INITAL CRITCALTYY SCOPING STUDIES FOR HOMOGENEOUS DRY SYSTEMS}

To achieve an independent means of ersuring subcriticality, various materials were considered. Solid pellets of gadolinium, tungsten, boron, and other strong absorbers were all proposed. Indeed, recycling the empty stainless-stcel cladding hulls through the dissolver was even considered. As a bare minimum, the amount (i.e., volume fraction) of any such material mixed with the fuel would have to be large enough that an infinite* dry system would remain subcritical. While some of the absorbers named above do have epithermal capture resonances, the bulk of the parasitic absorption still occurs at thermal energies where most have a large $1 / v$ cross section. Of the absorbers mentioned above, boron in the form of $\mathrm{B}_{4} \mathrm{C}$ was chosen for several reasons:

I. In addition to having a large !/v thermal cross section, it has a very low mass number. Because of that, the boron itself can provide the extra moderation required to capitalize on the large $I / v$ thermal cross section. (This is particularly important for the dry systems described above.)

2. Because of its low mass number and physical density $(g / \propto)$ one can have many more boron atoms per unit volume than gadolinium atoms per unit volume, thus making the macroscupic cruss section substantially larger.

3. Boron is abundant, cheap, and wiaely used in other nuclear engineering applications.

The first task, therefore, was to find the amount (i.e., the volume fraction) of $\mathrm{B}_{4} \mathrm{C}$ and/or stainless st el that should be mixed with the FFTF fuel described in Table $I$ so as to ensure, as a bare minimum, that an infinite dry system would remain subcritical. As a matter of convenience and econorr.y, this initial scoping study was performed using the CSASI criticality safety analysis module' assuming an infinite homogeneous mixture of fuel, stainless steel, and $B_{4} C$. The automated procedure used for generating the actual CSASI inpue is listed in Appendix A. As shown in Table 2, the volume fraction of fuel in the mixture ${ }^{\dagger}$

$$
\mathrm{VF}_{\mathrm{f}}=\operatorname{Vol}\left(\mathrm{MO}_{2}\right) /\left[\operatorname{Vol}\left(\mathrm{MO}_{2}\right)+\operatorname{Vol}\left(\mathrm{B}_{4} \mathrm{C}\right)+\operatorname{Vol}(\mathrm{SS})\right]
$$

\footnotetext{
"To be considered "independent" of the single contingency contrcls, one must assume that there is no mass control. Hence, all the studies in this report were based on infinite systems. [While conservative in all cases, and very conservative $n$ some, the approximation of the 30 -inch diameter $x 7$ feet Jong rotary dissolver as a "neutronically infinite system" can be shown to be fairly realistic in many cases, depending on the relative amount and spatial distribution of the various materials (including water) in the physical systenı.j

$+\mathrm{MO}_{2}$ denotes the plutonium/uranium mixed-oxide fuel described in Table 1, and Vol(SS) denotes all of the stainless-steel in the system (including the spent fuel cladding hulls and any additional stainless-steel associated with the $\mathrm{B}_{4} \mathrm{C}$ pellets).
} 
was varied from $1 \%$ to $100 \%$, and the fraction of $\mathrm{B}_{4} \mathrm{C}$ in the remaining volume

$$
V_{F_{b}}=\operatorname{Vol}\left(B_{4} C\right) /\left[\operatorname{Vol}\left(B_{4} C\right)+\operatorname{Vol}(S S)\right]
$$

was varied from 0\% to 95\%." In Table 2, calculated values of the neutron multiplication factor $\left(k_{\infty}\right)$ are flagged with a plus sign while the others were obtained by linear interpolation. Within the primary range of interest $\left(0.85 \leqslant k_{\infty} \leqslant 1 . C\right)$, the calculations were performed on a more frequent basis $\left(\Delta V F_{r} \approx 1 \%_{0}\right)$ than for those systems which were found to be far suberitical or far supercritical.

Table 1. Nuclide Concentrations for the Basic Materials Used in This Study.

\begin{tabular}{l|rrrr}
\hline Material & Nuclide & $\begin{array}{c}\text { Atoms/ } \\
\text { (barn-cm) }\end{array}$ & $\begin{array}{c}\text { Atoms } \\
\text { Nuclide }\end{array}$ & (barn-cr) \\
\hline FFTF & ${ }^{235} \mathrm{U}$ & $1.13954-4$ & ${ }^{238} \mathrm{Pu}$ & $9.03754-6$ \\
Fuel & ${ }^{238} \mathrm{U}$ & $1.57339-2$ & ${ }^{239} \mathrm{Pu}$ & $5.14180-3$ \\
$\left(\mathrm{MO}_{2)}\right.$ & ${ }^{16} \mathrm{O}$ & $4.26350-2$ & ${ }^{240} \mathrm{Pu}$ & $6.85991-4$ \\
& & & ${ }^{241} \mathrm{Pu}$ & $1.49021-4$ \\
& & & ${ }^{242} \mathrm{Pu}$ & $2.07688-5$ \\
\hline $\mathrm{B}_{4} \mathrm{C}$ & ${ }^{10} \mathrm{~B}$ & $2.05376-2$ & & \\
& ${ }^{11} \mathrm{~B}$ & $8.87050-2$ & & \\
& ${ }^{12} \mathrm{C}$ & $2.73107-2$ & & \\
\hline SS-316 & $\mathrm{Cr}$ & $1.52560-2$ & $\mathrm{Mo}$ & $1.21624-3$ \\
& $\mathrm{Mn}$ & $1.69917-3$ & $\mathrm{Si}$ & $1.66184-3$ \\
& $\mathrm{Fe}$ & $5.46723-2$ & $\mathrm{C}$ & $3.10878-4$ \\
& $\mathrm{Ni}$ & $9.54326-3$ & & \\
\hline Water & ${ }^{1} \mathrm{H}$ & $6.67593-2$ & & \\
& ${ }^{16} \mathrm{O}$ & $3.33797-2$ & & \\
\hline
\end{tabular}

The column where $V F_{b}=0.035$ is a special case in the sense that elemental boron was used in lieu of $\mathrm{B}_{4} \mathrm{C}$, with $\mathrm{VF}_{6}$ being defined as ( $\left.\mathrm{Vol}(\mathrm{B}) /[\mathrm{Vol}(\mathrm{B})+\mathrm{Vol}(\mathrm{SS})]\right)$ ). This particular case was of interest insofar as it corresponds to a commercially available type of borated stainless-steel ${ }^{3}$ containing $-1.2 \mathrm{wt}$ \% natural boron. 


\section{$5 / 6$}

Table 2. Neutron Muhtiplication Factor $\left(k_{x}\right)$ for Infinite Homogeneous Mixtures of $\mathrm{MO}_{2}, \mathrm{~B}_{4} \mathrm{C}$ and SS-316.

\begin{tabular}{|c|c|c|c|c|c|c|c|c|}
\hline$B_{t}$ & $1 *_{b}=0.000$ & $1 F_{b}=0.63 i$ & $60_{b} 7.150$ & $v F_{b}-0.300$ & $B r_{b}=0.300$ & $2 F_{b}=0.700$ & $6 F_{b}=6.890$ & $77_{b}=0.950$ \\
\hline 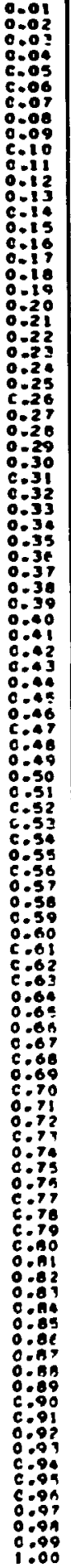 & 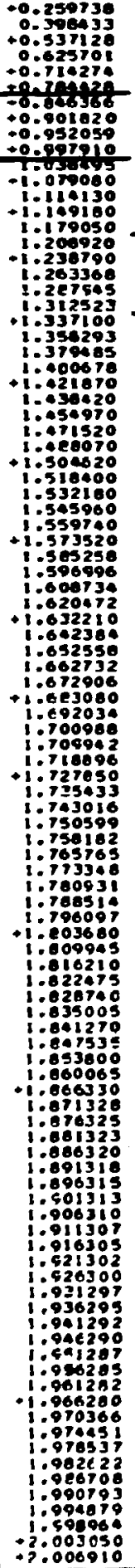 & 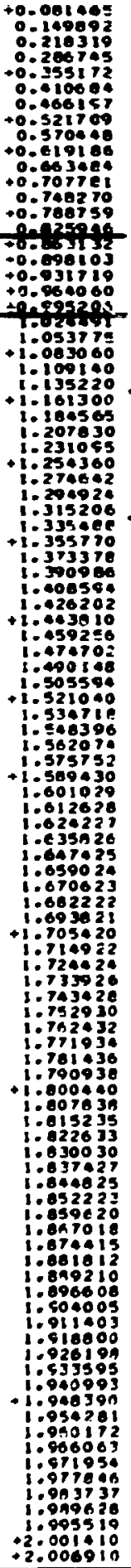 & 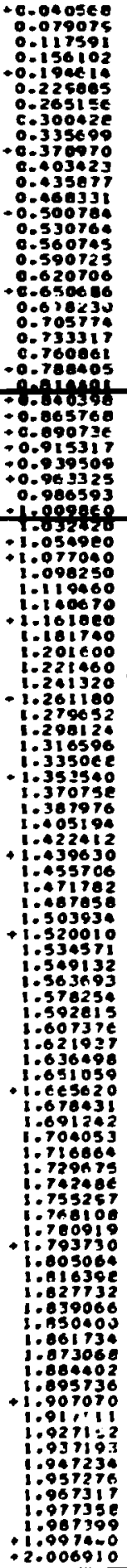 & 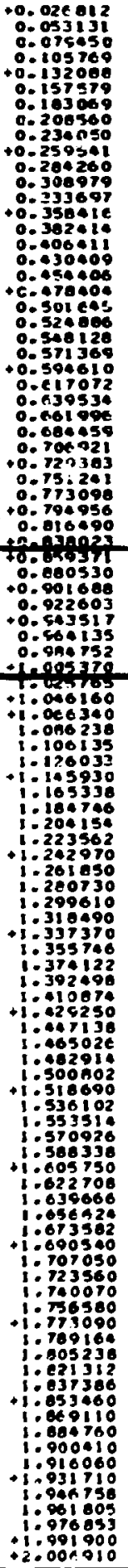 & 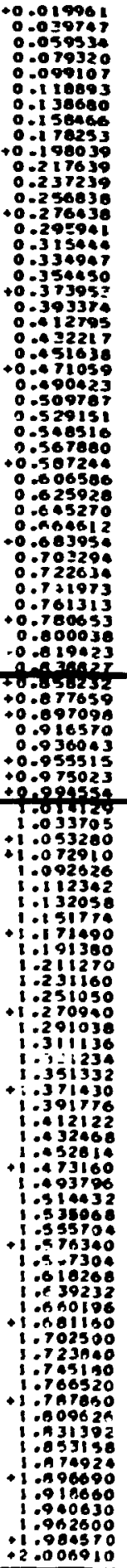 & 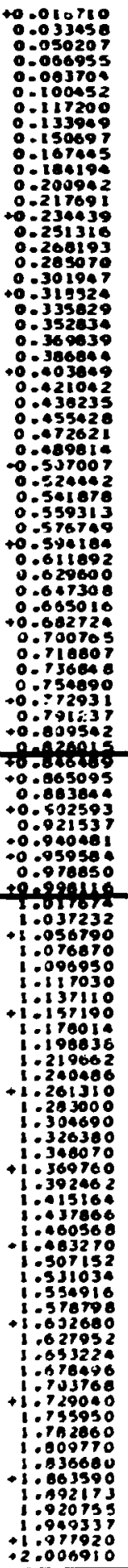 & 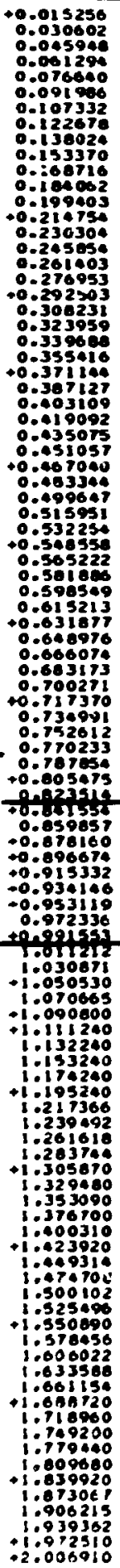 & 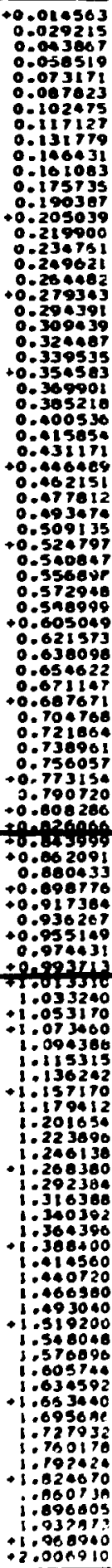 \\
\hline
\end{tabular}

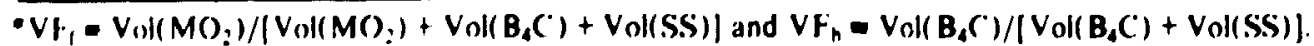

Note $A$ plus sign $(+)$ is used as a lag to denote calculated values: all other values are linearly incerpolated 


\section{EFFECT OF ADDITIONAL MODERATION ON THREE HOMOGENEOUS SYSTEMS OF INTEREST}

Looking at Table 2, a number of interesting observations may be made:

1. If one had only mixed oxide, the neutron multiplication factor $\left(k_{\infty}\right)$ would be -2.007 .

2. If one did not have any $B_{4} C$ and attempted to make the system subcritical merely by recirculating the cladding hulls and/or solid stainless-steel pellets, then the volume of the stainless steel in the uniform mixture would have to be at least ten times greater than that of the mixed oxide.

3. As $B_{4} C$ is introduced into the system, the amount of fuel allowed in the system increases dramatically from $\sim 9$ vol $\%\left(\right.$ when $V F_{b}=0 \%$ ) to $\sim 54$ vol $\%$ (when $V F_{b}=70 \%$ ); at higher $B_{4} C$ concentrations $\left(V F_{b} \geq 70 \%\right)$, the incremental benefit is not nearly as great. Assuming $k_{\infty}=0.95$ to be safely subcritical, one may use Table 2 to see how VF, varies as a function of VF

While Table 2 wiil be referenced several times throughout this report, there are at least three cases* showl: there that are of more immediate interest:

(a) If at least $30 \%$ of the mixture (by volume) is to be mixed oxide, then at least $15 \%$ of the remaining volume must be $B_{4} C\left[V F_{f}=0.30, V F_{b}=0.15\right]$.

(e) If the cladding on the $\mathrm{B}_{4} C$ peliets is thin enough that $95 \%$ of the steel-clad $\mathrm{B}_{4} C$ pellet is $\mathrm{B}_{4} C_{\text {, }}$ then at most $60 \%$ of the volume of the mixture may be mixed oxide [VF $=0.60, V F_{b}=0.95$ ].

(c) Because (a) and (e) represent two extremes, an intermediate case was also considered in which $49 \%$ of the mixture was mixed oxide, and $50 \%$ of the remaining volume was $\mathrm{B}_{4} \mathrm{C}$ $\left[V F_{f}=0.49, V F_{b}=0.50\right]$.

For the infinite dry system, all three cases $[(a),(c)$, and $(e)]$ will yield $k_{\infty}=0.95 \pm 0.01$.

Table 2 may be used to identify any number of infinite dry systems [VF, $V F_{b}$ ] which are safely subcritical. Indeed, three systems of potential interest $[(\mathrm{a}),(\mathrm{c})$, and (c)] have been identified. That the infinite dry system be safeiy subcritical is a necessary but not sufficient condition for acceptance. More specifically, it must be shown that the infinite homogeneous media defined by

$$
\begin{aligned}
& V_{F_{t}}=\operatorname{Vol}\left(\mathrm{MO}_{2}\right) /\left[\operatorname{Vol}\left(\mathrm{MC}_{2}\right)+\operatorname{Vol}\left(\mathrm{B}_{4} \mathrm{C}\right)+\operatorname{Vol}(\mathbf{S S})\right] \\
& \mathrm{VF}_{\mathrm{b}}=\operatorname{Vol}\left(\mathrm{B}_{4} \mathrm{C}\right) /\left[\operatorname{Vol}\left(\mathrm{B}_{4} \mathrm{C}\right)+\operatorname{Vol}\left(\mathrm{SS}_{\mathbf{S}}\right)\right]
\end{aligned}
$$

will remain safely subcritical at all $\mathrm{H} / \mathrm{Pu}$ ratios as water is uniformly added to the mixture. Indeed, were it not for the strong thermal absorber $\left(B_{4} C\right)$, the neutron multiplication factor $\left(k_{x}\right)$ may increase markedly as water is added to the dry system, with $k_{\infty}$ decreasing only after so much vater has been added that parasitic capture by the water begins to dominate over the enhanced moderation effect. With the $\mathrm{B}_{4} \mathrm{C}$ present in the system to varying degree [as represented by cases (a), (c), and (e)], the actual dependence of $k_{\infty}$ on the $H / P u$ ratio is not obvious. To assess this effect, the three homogeneous media described above as

-The original letters used to designate the various cases [(a),(c),(e),...] have been retained in this report to facilitate luture cross-referencing of these results with the original calculations and corresponding microfiche output. As such, the calculations reported here represent only a subset of those which have been performed and retained on file for quality assurance purposes. 
Case (a) $V F_{t}=0.30, V F_{b}=0.15$
Case (c) $V F_{t}=0.49, V F_{b}=0.50$
Case (c) $V F_{t}=0.60, V F_{b}=0.95$

were each diluted uniformly with water to obtain various $\mathrm{H} / \mathrm{Pu}$ ratios between $\mathrm{O}$ and 1600 . At each H/Pu ratio, a CSAS1 calculation was performed to determine thr i.eutron multiplication factor $\left(k_{\infty}\right)$ for each mixture. The automated procedure used for generating the actual CSASI input is listed in Appendix B. The results of these calculations are shown in Table 3 and Fig. 1. Note that in all three cases, the neutron multiplication factor $\left(k_{\infty}\right)$ deareases monotonically from -0.95 to something $\leq 0.4$ as the $\mathrm{H} / \mathrm{Pu}$ ratio is increased from 0 to 70 . From Fig. 1, it would then appear that the three values of $k_{\infty}$ remain about constant as the $\mathrm{H} / \mathrm{Pu}$ ratio is increased from 70 to 1000. More careful scrutiny of Table 3 will reveal, however, that each of the three sets of Cata do show $k_{\infty}$ as passing through a very slight peak as the $H / P u$ ratio is raised from 70 to 1000 . Although slight, all three sets of tabulated data do show a definite downward trend as the $\mathrm{H} / \mathrm{Pu}$ ratio is raised from 500 to 1000 . The slight peak that is seen at an $H / P u$ ratio of $\sim 300$ is a resonance self-shielding effect which can be shown mathematically to ocelr only at the optimum $\mathrm{H} / \mathrm{Pu}$ ratio for the given mixture (i.e., $\mathrm{k}_{\mathrm{oc}}$ will thereafter decrease monotonically as a function of the $\mathrm{H} / \mathrm{Pu}$ ratio). 
Table 3. Neutron Multiplication Factor $\left(k_{\infty}\right)$ as a Function of the H/Pu Ratio for Several Infinite Homogeneous Mixtures of $\mathrm{MO}_{2}, \mathrm{H}_{2} \mathrm{O}, \mathrm{B}_{4} \mathrm{C}$, and SS-316.

\begin{tabular}{|c|c|c|c|}
\hline $\mathbf{H} / \mathbf{P u}$ & $\begin{array}{c}\text { Case (a) } \\
V F_{r}=0.30 \\
V F_{b}=0.15\end{array}$ & $\begin{array}{c}\text { Case }(c) \\
V F_{f}=0.49 \\
V F_{b}=0.5 C\end{array}$ & $\begin{array}{c}\text { Case (e) } \\
V F_{f}=0.60 \\
V F_{b}=0.95\end{array}$ \\
\hline $1.00 \mathrm{E}-03$ & 0.939509 & 0.955515 & 0.955149 \\
\hline $3.50 \mathrm{E}-02$ & 0.935038 & 0.950859 & 0.950701 \\
\hline 1.00E-01 & 0.927012 & 0.942446 & 0.942624 \\
\hline 2.10E-01 & 0.914405 & 0.928581 & 0.929346 \\
\hline 4.00E-0I & 0.894069 & 0.906671 & 0.908053 \\
\hline $6.50 \mathrm{E}-01$ & 0.870390 & 0.880715 & 0.882516 \\
\hline $1.00 \mathrm{E}+00$ & 0.841890 & 0.848865 & 0.850728 \\
\hline $1.45 \mathrm{E}+00$ & 0.811258 & 0.813942 & 0.815316 \\
\hline $2.00 \mathrm{E}+00$ & 0.780472 & 0.778207 & 0.778488 \\
\hline $3.50 \mathrm{E}+00$ & 0.719441 & 0.705925 & 0.702334 \\
\hline $6.00 \mathrm{E}+00$ & 0.655663 & 0.629361 & 0.619777 \\
\hline $9.50 \mathrm{E}+00$ & 0.600887 & 0.563805 & 0.548330 \\
\hline $1.50 \mathrm{E}+01$ & 0.549024 & 0.502987 & 0.481359 \\
\hline $2.30 \mathrm{E}+01$ & 0.503885 & 0.451691 & 0.426249 \\
\hline $3.50 \mathrm{E}+01$ & $0.47250 ?$ & 0.409735 & 0.380589 \\
\hline $5.00 \mathrm{E}+0 \mathrm{i}$ & $0.45: 630$ & 0.382997 & 0.350107 \\
\hline $7.00 E+01$ & 0.448943 & 0.366751 & 0.330473 \\
\hline $1.00 \mathrm{E}+02$ & 0.450381 & 0.359149 & 0.318841 \\
\hline $1.45 E^{\prime} 02$ & 0.457266 & 0.359522 & 0.315 .53 \\
\hline $2.00 \mathrm{E}+02$ & 0.453346 & 0.363169 & 0.317705 \\
\hline $2.50 \mathrm{E}+02$ & 0.465695 & 0.365542 & 0.319765 \\
\hline $3.00 \mathrm{E}+02$ & 0.465827 & 0.366528 & 0.320996 \\
\hline $4.00 \mathrm{E}+02$ & 0.462195 & 0.365322 & 0.320903 \\
\hline $5.00 \mathrm{E}+02$ & 0.456123 & 0.361627 & 0.318491 \\
\hline $6.00 \mathrm{E}+02$ & 0.449251 & 0.356814 & 0.314851 \\
\hline $8.00 E+02$ & 0.435550 & 0.346333 & C.306270 \\
\hline $1.00 \mathrm{E}+03$ & $0.42308 I$ & 0.336293 & 0.297644 \\
\hline
\end{tabular}

ivote: $\quad \mathrm{VF}_{\mathrm{f}}=\operatorname{Vol}\left(\mathrm{MO}_{2}\right) /\left[\operatorname{Vol}\left(\mathrm{MO}_{2}\right)+\operatorname{Vol}\left(\mathrm{B}_{4} \mathrm{C}\right)+\operatorname{Vol}(\mathrm{SS})\right]$.

$V^{\prime} F_{b}=\operatorname{Vol}\left(B_{4} C\right) /\left[\operatorname{Vol}\left(B_{4} C\right)+\operatorname{Vol}(S S)\right]$. 
ORNL - DWG $82 \cdot 20660^{\circ}$

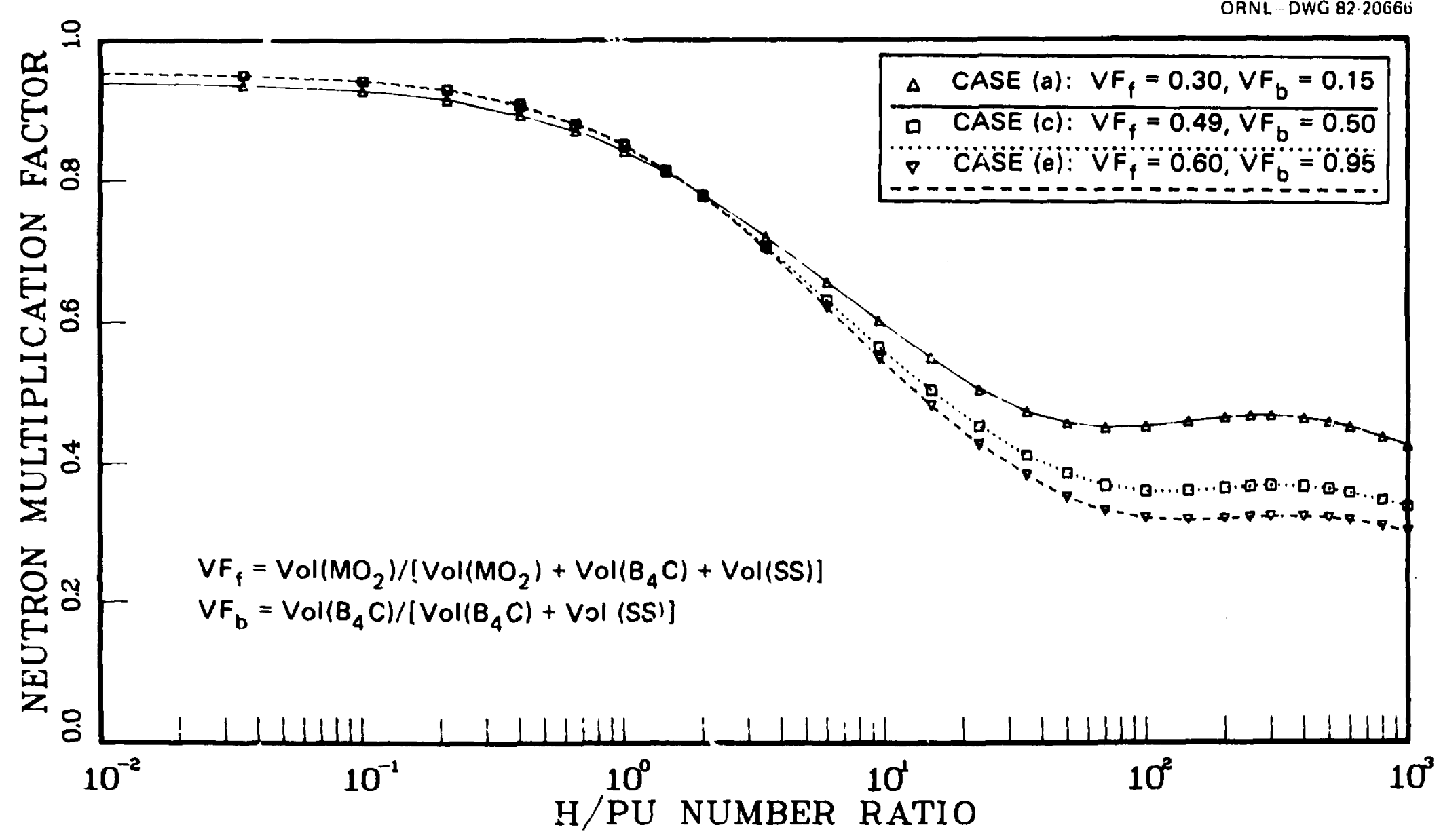

Fig. 1. Neutron Multiplication Factor $\left(k_{\infty}\right)$ as a Furction of the $H / F u$ Ratio for Several Infinite Homogeneous Mixtures of $\mathrm{MO}_{2}, \mathrm{H}_{2} \mathrm{O}, \mathrm{B}_{4} \mathrm{C}$, and SS 316 . 


\section{EFFECT OF SPATIAL-SELF_SF 'ELDING IN LARGE B,C PELLETS FOR SEVERAL DIFFERENT SYSTEMS}

While Table 3 and Fig. I do show the three infinite homogeneous media [(a), (c), (e)] to be safely subcritical at all $\mathrm{H} / \mathrm{Pu}$ ratios, those results should not be taken too seriously. In particular, one should note that the peak in $k_{\infty}$ at higher $\mathrm{H} / \mathrm{Pu} \mathbf{r}$-ios was uncharacteristically flat for two reasons: First, a thermal absorber $\left(\mathrm{B}_{4} \mathrm{C}\right)$ was present in the system. Secondly, and even more important, the $\mathrm{B}_{4} \mathrm{C}$ was distributed uniformly with the fuel and moderator $\left(\mathrm{H}_{2} \mathrm{O}\right)$. The close proximity of all the boron atoms to the source of the thermal neutrons (i.e., scattering collisions with hydrogen) in this homogenized model allows each boron atom to be very effective in absorbing the thermal neutrons before they have much chance to be absorbed by the fuel. In reality, of course, the $\mathrm{B}_{4} \mathrm{C}$ will necessarily be lumped into some type of steel-clad pellet. While those boron atoms near the surface remain quite effective, those further on the interior see, and subsequently absorb, fewer and fewer thermal neutrons. This spatial-self-shielding effect thus reduces the average effectiveness of the boron as a neutron poison. As the $B_{4} C$ lumps get larger, the average effectiveness of the boron in a well thermalized system will diminish, the neutron multiplication factor $\left(k_{\infty}\right)$ will tend to rise, and the peak in the $k_{\infty}$ vs $\mathrm{H} / \mathrm{Pu}$ curve will become more pronounced.

To determine the importance of this spatial-self-shielding effect, a fairly simple one-dimensional spherical model was considered in which a stainless-steel-clad $\mathrm{B}_{4} \mathrm{C}$ pellet having a 0.5 -inch outside diameter was surrounded by a homogeneous mixture of mixed oxide and water. The three systems previously described as

$$
\begin{aligned}
& \text { Case (a): } V F_{f}=0.30, V_{b}=0.15 \\
& \text { Case (c): } V F_{f}=0.49, V_{b}=0.50 \\
& \text { Case (c): } V F_{f}=0.60, V F_{b}=0.95
\end{aligned}
$$

were then studied as a function of the $\mathrm{H} / \mathrm{Pu}$ ratio. In the calculational models, the outer radius of the steel-clad pellet $\left(r_{2}\right)$ was arbitrarily fixed at 0.25 inches. [Physically, of course, the outer radius of the steel-clad $\mathrm{B}_{4} \mathrm{C}$ pellet might actually be somewhat less, with the additional steel in the calculational model representing the spent fuel cladding hu'.s. See Section V.A. V.C, and Appendix D for additional details.] Knowing

$$
\left.V F_{b}=\operatorname{Voií} B_{4} C\right) /\left[\operatorname{Vol}\left(B_{4} C\right)+\operatorname{Vol}(S S)\right]=r_{1}{ }^{3} / r_{2}{ }^{3} \text {. }
$$

the radius of the $B_{4} C\left(r_{1}\right)$ could be fixed for the particular system of interest [(a), (c), (e)]. Knowing

$$
\mathrm{VF}_{\mathrm{r}}=\operatorname{Vol}\left(\mathrm{MO}_{2}\right) /\left[\operatorname{Vol}\left(\mathrm{MO}_{2}\right)+\operatorname{Vol}\left(\mathrm{B}_{4} \mathrm{C}\right)+\operatorname{Vol}(\mathrm{SS})\right]=\frac{\mathrm{r}_{3}{ }^{3}-\mathrm{r}_{2}{ }^{3}}{\mathrm{r}_{3}{ }^{3}}
$$

the outer radius of the unit cell in the dry system $\left(r_{3 D}\right)$ could then be calculated as $\mathrm{r}_{3 \mathrm{D}}=\mathrm{r}_{2}\left(1-V \mathrm{~F}_{\mathrm{f}}\right)^{-\mathrm{th}}$

The amount of water required to obtain any desired $\mathrm{H} / \mathrm{Pu}$ ratio could then be calculated using the data in Table 1. Knowing $\operatorname{Vol}\left(\mathrm{MO}_{2}\right)$ and $\operatorname{Vol}\left(\mathrm{H}_{2} \mathrm{O}\right)$, the outer radius of the homogenized fuel/water zone $\left(r_{3}\right)$ could be determined for a similar unit cell in a wet system having the given $\mathrm{H} / \mathrm{Pu}$ ratio. The one-dimensional $\mathrm{S}_{8} \mathrm{P}_{3}$ transport calculations for each of the three systems at each $\mathrm{H} / \mathrm{Pu}$ ratio were then performed using the CSASI criticality safety analysis module. The automated procedure used for generating the actual CSASI input is listed in Appendix C. The results

\footnotetext{
- Because a strong neutron poison was located in the center of the spherical model, the CSASI calculations were performed using the multiregion option, with one external moderator assigned to the fuel/water mixture in zone 3 . Of the various ways the 1-D problem could be modeled in the SCALE system, this seemed to be the most realistic and cust-effective. A slightly more realistic CSAS2/KENO-IV model is described in Section VI.
} 
of these calculations are shown in Table 4. Because the results of all three cases [(a), (c), (c)] are so similar, only the results of case (e) are shown in Fig. 2. Note that, unlike the homogeneous case, all three lumped systems [(a), (c), (e)] exhibit a very proncunced peak in the nentron multiplication factor $\left(k_{\infty}\right)$ at an $H / P u$ ratio of -600 . That a peak does occur at some $H / P u$ ratio is primarily a resonance-self-shielding effect (just as in the homogeneous case). That the peak is so large and unsurpressed (relative to the homogenized case) is primarily due to the spatial-self-shielding in the steel-clad $\mathrm{B}_{4} \mathrm{C}$ pellet.

As shown in Table 4 and Fig. 2, all three lumped systems had a maximum $k_{\infty}$ of $\sim 1.3$ when the H/Pu ratio was -600 . In the third case, case (e), 60 vol $\%$ of the dry system was mixed oxide and $95 \mathrm{vol}$ \% of the steel-clad $\mathrm{B}_{4} \mathrm{C}$ pellet was actually $\mathrm{B}_{4} \mathrm{C}$. From that calculation it became obvious that the projected fuel loading would have to be reduced. The other two cases, (a) and (c), had substantially lower fuel concentrations (of $30 \mathrm{vol} \%$ and 50 vol $\%$, respectively). While they were also supercritical, the amount of $B_{4} C$ used in each case $\left(V F_{b}=0.15\right.$ and $\left.V F_{b}=0.50\right)$ was substantially less than the maximum. To determine whether either of these cases $\left(V_{f}=0.30\right.$ or $V F_{1}=0.50$ ) could be made subcritical, the amount of $\mathrm{B}_{4} \mathrm{C}$ contained in the 0.5 -inch steel-clad pellets :vas increased to 95\%. These two new cases

$$
\begin{aligned}
& \text { Case }\left(a^{\prime}\right): V F_{I}=0.30, V F_{b}=0.95 \\
& \text { Case }\left(c^{\prime}\right): V F_{!}-0.49, V F_{b}=0.95
\end{aligned}
$$

were then examined as a function of the $\mathrm{H} / \mathrm{Pu}$ ratio. The results of these one-dimensional CSASI calculations are shown along with the earlier results in Table $S$, and in Fig:. 3a and 3b. While the additional $\mathrm{B}_{4} \mathrm{C}$ reduced $k_{\infty}$ of the dry systems from $\sim 0.95$ to 0.45 and 0.76 , respectively, its impact on $k_{\infty}$ in the optimally moderated range was less pronounced. In the first case ['a) and $\left(a^{\prime}\right)$ ], the additional $B_{4} C$ reduced the peak value of $k_{\infty}$ from 1.268 down to 0.979 ; in the second case $\left[(c)\right.$ and $\left.\left(c^{\prime}\right)\right]$, it reduced the peak value of $k_{\infty}$ from 1.300 down to 1.215 . While the one case [(a')] was stightly subcritical, the peak neutron multiplication factor was still unacceptally high, and the fissile loading $\left(\mathrm{VF}_{\mathrm{f}}\right)$ was disappointingly low.

*These values are in good agreement with the values for the corresponding dry homogeneous caleulations shown in Table I (i.e., 0.446 and 0.756 ). 
Table 4. Neutron Multiplication Factor $\left(k_{\infty}\right)$ as a Function of the $H / P u$ Ratio for Several Systems in Which 0.5-inch-Diameter Steel-Clad B4C Pellets are Uniíormly Dispersed in a Homogeneous Mixture of Fuel and Water.

\begin{tabular}{|c|c|c|c|}
\hline $\mathrm{H} / \mathrm{Pu}$ & $\begin{array}{c}\text { Case (a) } \\
V E_{f}=0.30 \\
V F_{b}=0.15\end{array}$ & $\begin{array}{c}\text { Case }(c) \\
V F_{f}=0.49 \\
V F_{b}=0.50\end{array}$ & $\begin{array}{c}\text { Case (e) } \\
V F_{f}=0.60 \\
V F_{b}=0.95\end{array}$ \\
\hline $1.00 \mathrm{E}-03$ & 0.943726 & 0.960408 & 0.959013 \\
\hline $3.57 \mathrm{E}-02$ & 0.939531 & 0.956058 & 0.955384 \\
\hline $1.00 E-01$ & 0.932035 & 0.948164 & 0.947679 \\
\hline 2. $\mid 0 E-01$ & 0.920132 & 0.935624 & 0.935344 \\
\hline $4.00 \mathrm{E}-01$ & 0.901661 & 0.915819 & $0.9156 \hat{z} 3$ \\
\hline $6.50 E-01$ & 0.880688 & 0.892809 & 0.892304 \\
\hline $1.00 \mathrm{E}+00$ & 0.856204 & 0.865280 & 0.863901 \\
\hline $1.45 E+00$ & 0.831042 & 0.836012 & 0.832972 \\
\hline $2.00 E+00$ & 0.807011 & 0.807234 & 0.801837 \\
\hline $3.50 \mathrm{E}+00$ & 0.763927 & 0.753170 & 0.741295 \\
\hline $6.00 \mathrm{E}+00$ & 0.727151 & 0.704189 & 0.683775 \\
\hline $9.50 E+00$ & 0.706073 & 0.673723 & 0.646179 \\
\hline $1.50 \mathrm{E}+01$ & 0.701765 & 0.663975 & 0.631247 \\
\hline $2.30 \mathrm{E}+01$ & 0.722737 & 0.683619 & 0.649108 \\
\hline $3.50 \mathrm{E}+01$ & 0.771332 & 0.735763 & 0.703124 \\
\hline $5.00 \mathrm{E}+01$ & 0.833940 & 0.804977 & 0.776705 \\
\hline $7.00 \mathrm{E}+01$ & 0.406835 & 0.886279 & 0.863813 \\
\hline $1.00 \mathrm{E}+02$ & 0.991549 & 0.981622 & 0.966162 \\
\hline $1.45 \mathrm{E}+02$ & 1.079520 & 1.081130 & 1.073330 \\
\hline $2.00 \mathrm{E}+02$ & I. 148740 & 1.159900 & 1.158130 \\
\hline $2.50 \mathrm{E}+02$ & 1.190070 & 1.207280 & 1.209110 \\
\hline $3.00 \mathrm{E}+02$ & 1.218420 & 1.240050 & 1.244470 \\
\hline $4.00 E+02$ & 1.251250 & 1.278440 & 1.286310 \\
\hline $5.00 E+02$ & 1.265050 & 1.295400 & 1.305170 \\
\hline $6.00 \mathrm{E}+02$ & 1.267840 & 1.299910 & 1.310840 \\
\hline 8.00E +02 & 1.255280 & 1.288460 & 1.300410 \\
\hline $1.00 E+03$ & 1.230450 & 1.263200 & 1.275310 \\
\hline $1.20 \mathrm{E}+03$ & 1.200220 & 1.231890 & 1.243780 \\
\hline $1.40 \mathrm{E}+03$ & 1.167840 & 1.198090 & 1.209600 \\
\hline $1.60 \mathrm{E}+03$ & 1.134930 & 1.163710 & 1.174730 \\
\hline $1.80 \mathrm{E}+03$ & 1.102380 & 1.129640 & 1.140120 \\
\hline $2.00 \mathrm{E}+03$ & 1.070640 & 1.096440 & 1.106360 \\
\hline $2.40 \mathrm{E}+03$ & 1.010580 & 1.033640 & 1.042550 \\
\hline $3.00 E+03$ & 0.929748 & 0.949301 & 0.956880 \\
\hline $3.7 \iota+03$ & 0.848696 & 0.864985 & 0.871317 \\
\hline $4.60 E+03$ & 0.762033 & 0.775134 & 0.780234 \\
\hline $5.60 E+03$ & 0.683664 & 0.694200 & 0.698295 \\
\hline $7.00 E+03$ & 0.597124 & 0.605129 & 0.608240 \\
\hline $8.50 E+03$ & 0.525542 & 0.5 .91721 & 0.534130 \\
\hline $1.00 E+04$ & 0.469094 & 0.474013 & 0.475932 \\
\hline
\end{tabular}

Note: $\quad V_{F_{f}}=\operatorname{Vol}\left(\mathrm{MO}_{2}\right) /\left[\operatorname{Vol}\left(\mathrm{MO}_{2}\right)+\operatorname{Vol}\left(\mathrm{B}_{4} \mathrm{C}\right)+\operatorname{Vol}(\mathrm{SS})\right]$

$V F_{b}=\operatorname{Vol}\left(B_{4} C\right) /\left[\operatorname{Vol}\left(B_{4} C\right)+\operatorname{Vol}(S S)\right]$ 


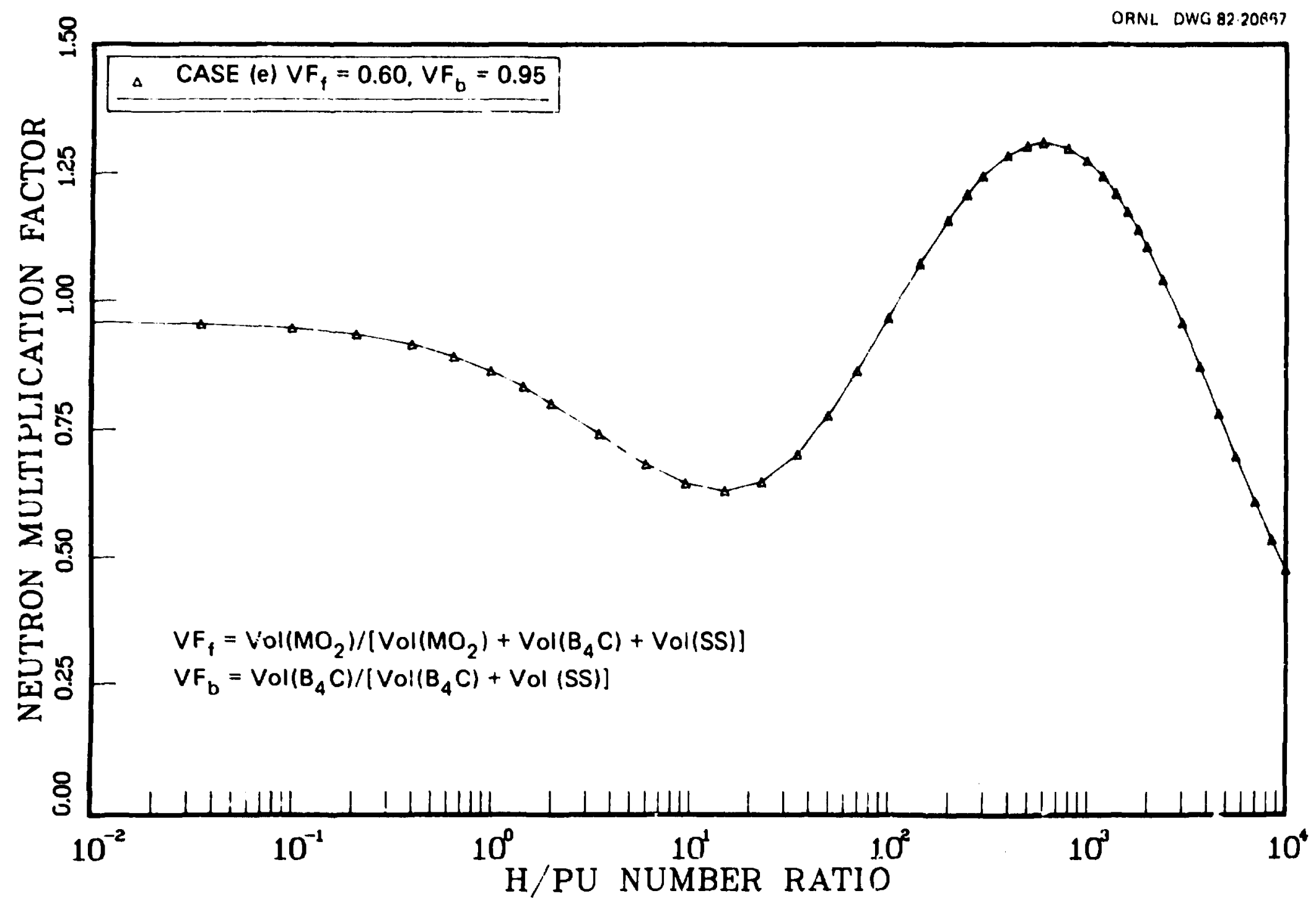

Fig. .. Neutron Multiplication Factor $\left(k_{\infty}\right)$ as a Function of the H/Pu Ratio for One System in Which 0.5-inchDiameter Stecl-Clad $B_{+} C$ Pellets are Uniformly Dispersed in a Homogenized Mixture of Fuel and Water $\left(V F_{1}=0.60, V F_{h}=0.95\right)$. 
Table 5. Neutron Multiplication Factor $\left(k_{\infty}\right)$ as a Function of the H/Pu Ratio for Several Other Systems in Which 0.5-inch-Diameter Steel-Clad B,C Pellets are Uniformly Dispersed in a Homogeneous Mixture of Fuel and Water.

\begin{tabular}{|c|c|c|c|c|}
\hline $\mathbf{H} / \mathbf{P u}$ & $\begin{array}{c}\text { Case (a) } \\
V F_{f}=0.30 \\
V F_{b}=0.15\end{array}$ & $\begin{array}{c}\text { Case ( }\left(a^{\prime}\right) \\
V F_{f}=0.30 \\
V F_{b}=0.95\end{array}$ & $\begin{array}{c}\text { Case (c) } \\
V F_{f}=0.49 \\
V F_{b}=0.50\end{array}$ & $\begin{array}{r}\text { Case }\left(c^{\prime}\right) \\
V F_{f}=0.49 \\
V F_{b}=0.95\end{array}$ \\
\hline $1.00 \mathrm{E}-03$ & 0.943726 & 0.450158 & 0.960408 & 0.760201 \\
\hline 3.50E-02 & 0.939531 & 0.449229 & 0.956058 & 0.757546 \\
\hline $1.00 \mathrm{E}-01$ & 0.932035 & 0.447529 & 0.948164 & 0.752720 \\
\hline $2.10 \mathrm{E}-01$ & 0.920132 & 0.444703 & 0.935624 & 0.744828 \\
\hline 4.00E-01 & 0.901661 & 0.439969 & 0.915819 & 0.731953 \\
\hline $6.50 \mathrm{E}-01$ & 0.880688 & 0.433966 & 0.892809 & 0.716328 \\
\hline $1.00 \mathrm{E}+00$ & 0.856204 & 0.426119 & 0.865280 & 0.696564 \\
\hline $1.45 E+00$ & 0.831042 & 0.416732 & 0.836012 & 0.674360 \\
\hline $2.00 \mathrm{E}+00$ & 0.807011 & 0.406223 & 0.807234 & 0.651061 \\
\hline $3.50 \mathrm{E}+00$ & 0.763927 & 0.382140 & 0.753170 & 0.602857 \\
\hline $6.00 E+00$ & 0.727151 & 0.352531 & 0.704189 & 0.552607 \\
\hline $9.50 \mathrm{E}+00$ & 0.706073 & 0.324916 & 0.673723 & 0.514795 \\
\hline $1.50 \mathrm{E}+01$ & 0.701765 & 0.299872 & 0.663975 & 0.491941 \\
\hline $2.30 \mathrm{E}+01$ & 0.722737 & 0.284622 & 0.683619 & 0.495381 \\
\hline $3.50 \mathrm{E}+01$ & 0.771332 & 0.285722 & 0.735763 & 0.532671 \\
\hline $5.00 \mathrm{E}+01$ & 0.833940 & 0.306924 & 0.804977 & 0.595151 \\
\hline $7.00 \bar{E}+01$ & 0.906835 & 0.350041 & 0.886279 & 0.678185 \\
\hline $1.05 \mathrm{E}+02$ & 0.991549 & 0.422993 & 0.981622 & 0.784360 \\
\hline$! .45 E+02$ & 1.079520 & 0.525245 & 1.081130 & 0.903007 \\
\hline $2.00 \mathrm{E}+02$ & 1.148740 & 0.626965 & 1.159900 & 1.002020 \\
\hline $2.50 \mathrm{E}+02$ & 1.190070 & 0.699241 & 1.207280 & 1.064110 \\
\hline $3.00 \mathrm{E}+02$ & 1.218420 & 0.756483 & 1.240050 & 1.108950 \\
\hline $4.00 \mathrm{E}+02$ & 1.251250 & 0.838832 & 1.278440 & 1.165940 \\
\hline $5.00 \mathrm{E}+02$ & 1.265050 & 0.892570 & 1.295400 & 1.196500 \\
\hline $6.00 \mathrm{E}+02$ & 1.267840 & 0.928073 & 1.299910 & 1.211470 \\
\hline $8.00 \mathrm{E}+02$ & 1.255280 & 0.966050 & 1.288460 & 1.215330 \\
\hline $1.00 \mathrm{E}+03$ & 1.230450 & 0.978796 & $1.2632 \mathrm{CO}$ & 1.200890 \\
\hline $1.20 \mathrm{E}+03$ & 1.200220 & 0.977919 & 1.231890 & 1.177720 \\
\hline $1.40 E+03$ & 1.167840 & 0.969170 & 1.198090 & 1.150310 \\
\hline $1.60 \mathrm{E}+03$ & 1.134930 & 0.955804 & 1.163710 & 1.121100 \\
\hline $1.80 E+03$ & 1.102380 & 0.939704 & 1.129640 & 1.091290 \\
\hline $2.00 E+03$ & 1.070640 & 0.922030 & 1.096440 & 1.061700 \\
\hline $2.40 \mathrm{E}+03$ & 1.010580 & 0.884734 & 1.033640 & 1.004610 \\
\hline $3.00 \mathrm{E}+03$ & 0.929748 & 0.828900 & 0.949301 & 0.926410 \\
\hline $3.70 \mathrm{E}+03$ & 0.848696 & 0.768333 & 0.864985 & 0.847001 \\
\hline $4.60 \mathrm{E}+03$ & 0.762033 & 0.699797 & 0.775134 & 0.761394 \\
\hline $5.60 F+03$ & 0.683664 & 0.635127 & 0.694200 & 0.683603 \\
\hline $7.00 \mathrm{E}+03$ & 0.597124 & 0.561214 & 0.605129 & 0.597381 \\
\hline $8.50 \mathrm{E}+03$ & 0.525542 & 0.498369 & 0.531721 & 0.525914 \\
\hline $1.00 E+04$ & 0.469094 & 0.447823 & 0.474013 & 0.469499 \\
\hline
\end{tabular}

Nole: $\quad V F_{f}=\operatorname{Vol}\left(\mathrm{MO}_{2}\right) /\left[\operatorname{Vol}\left(\mathrm{MO}_{2}\right)+\operatorname{Vol}\left(\mathrm{B}_{4} \mathrm{C}\right)+\operatorname{Vol}(\mathrm{SS})\right]$ $V F_{b}=\operatorname{Vol}\left(B_{4} C\right) /\left[\operatorname{Vol}\left(B_{1} C\right)+\operatorname{Vol}(S S)\right]$ 


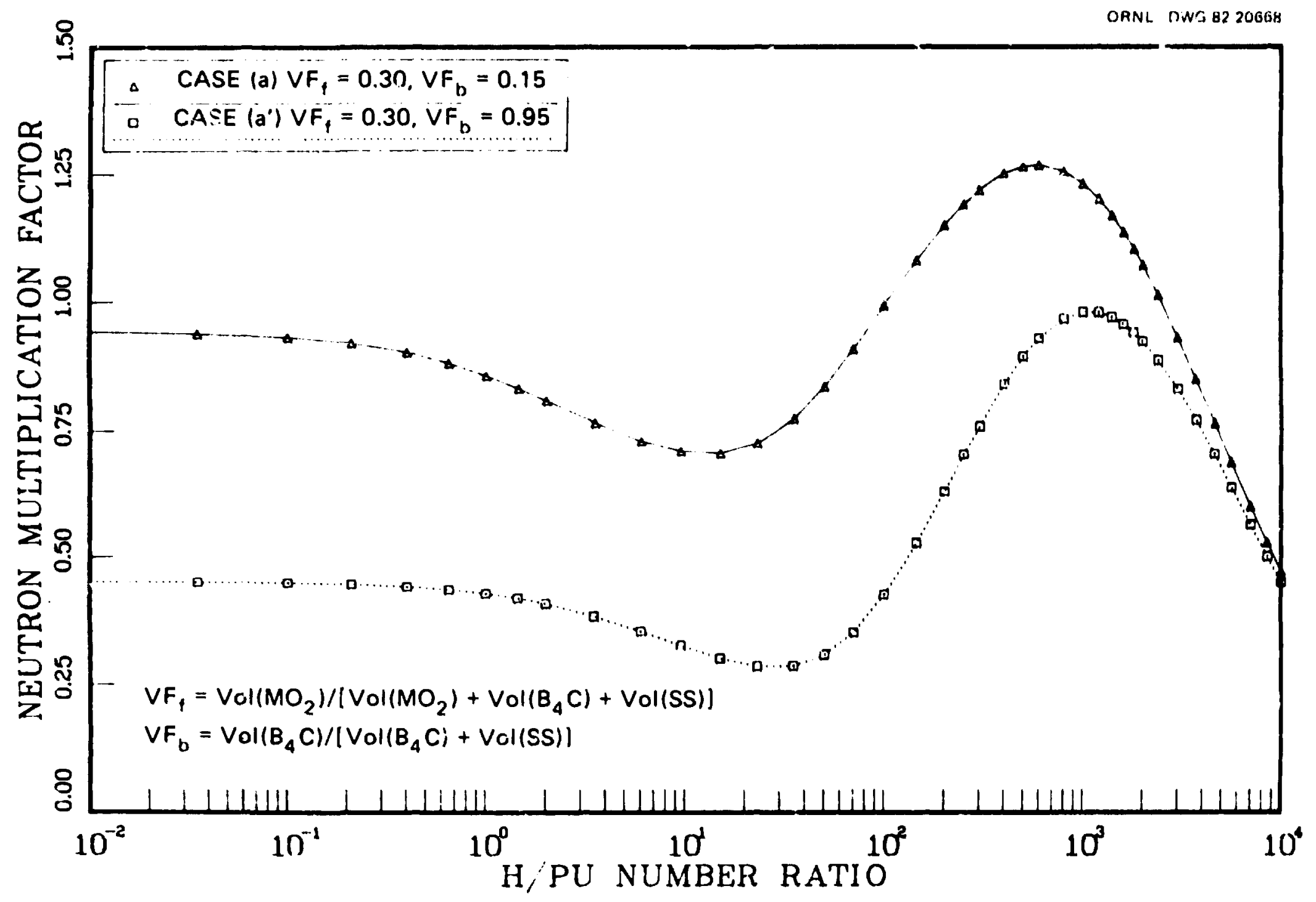

Fig. 3a. Neutron Multiplication Factor $\left(i_{x}\right)$ as a Function of the H/Pu Ratio for Two Different Systems in Which 0.5.inch-Diameter Steel-Clad $B_{4} C$ Pellets are Uniformly Dispersed in a Homogenized Mixture of Fuel and Water $\left(V F_{1}=0.30 ; V F_{b}=0.15\right.$ and $\left.V F_{b}=0.95\right)$. 


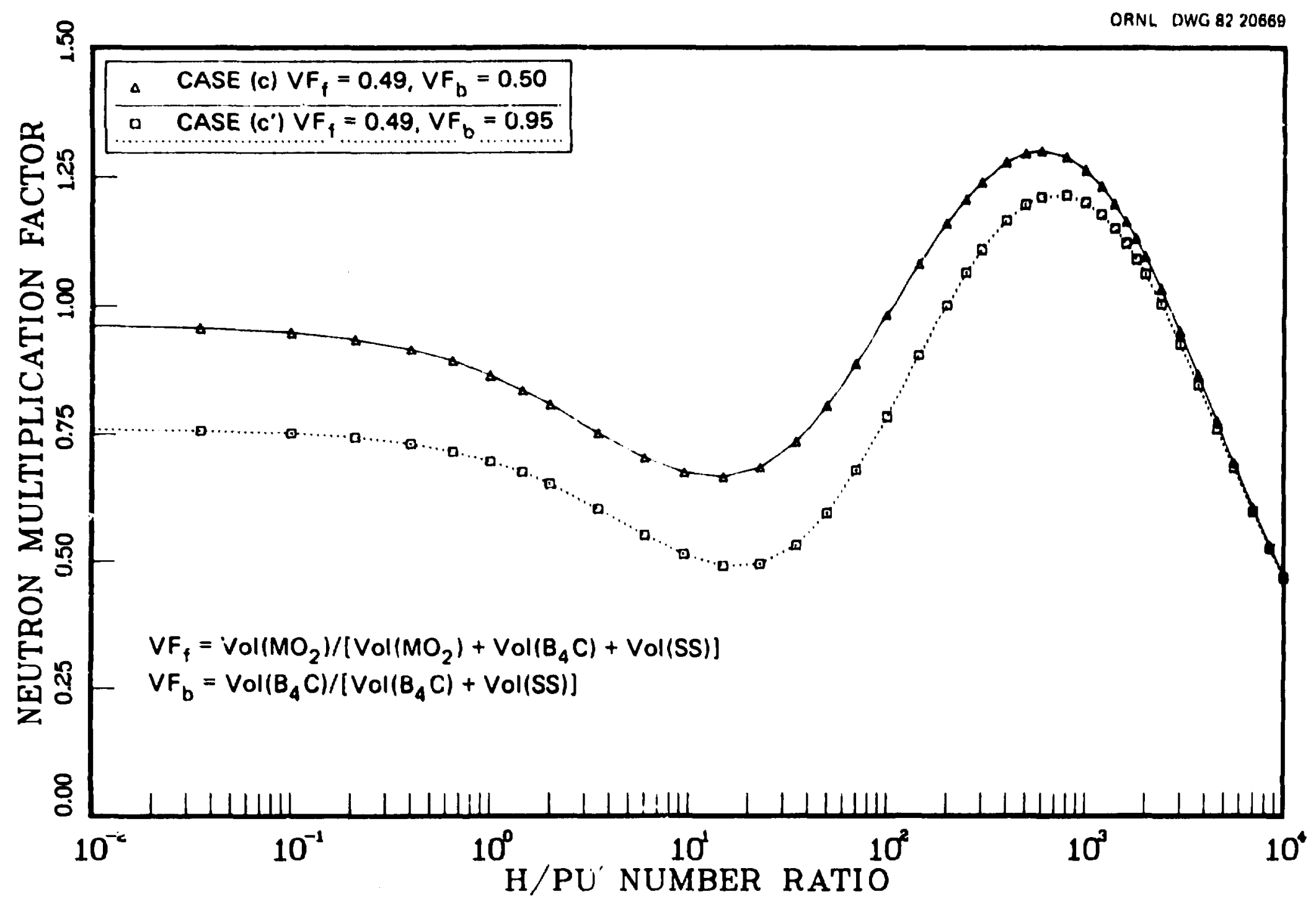

Fig. 3b. Neutron Multiplication Factor $\left(k_{\infty}\right)$ as a Function of the $H / P u$ Ratio for Two Diffe'ent Syatems in Which 0.5-inch-Diameter Steel-Clad $B_{4} C$ Pellets are Uniformly Dispersed in a Homogenized Mixture of Fuel a..d Water $\left(V F_{f}=0.49 ; F_{b}=0.50\right.$ and $\left.V F_{b}=0.95\right)$. 


\section{THE SEARCH FOR A WORKABLE SYSTEM}

\section{V.A. RESTRICTIONS ON THE SIZE AND COMPOSITION OF THE STEELCLAD $B_{4} C$ PELLETS}

From the results of the spatial-self-shielding calculations reported in the previous section, it was obvious that 0.5 -inch-diameter stecl-clad $\mathrm{B}_{4} \mathrm{C}$ pellets could not be used to make the infinite system safely subcritical under all conditions (i.e., to make $k_{\infty} \leqslant 0.95$ at all $H / P u$ ratios). Yet, as shown in Fig. 1 , the corresponding homogeneous systems were all subcritical, with $k_{\infty}$ decreasing in a nearly monotonic fashion as the H/Pu ratio was increased. From these observations it became obvious that:

1. A smaller diameter $B_{4} C$ pellet could certainly be used to make the heterogeneous system safely subcritical; and

2. The smaller the $B_{4} C$ pellet, the greater would be the allowable fissile loading $\left(V F_{f}\right)$.

There are, however, certain constraints on the minimum diameter of the steel-clad $\mathrm{B}_{4} \mathrm{C}$ pellet. First, if the diameter becomes too terribly small, the steel-clad pellet may be difficult or impossible to manufacture. Secondly, and even more important, the dianeter of the steel-elad $\mathrm{B}_{4} \mathrm{C}$ pellets should be roughly the same as the FFTF fuel $\left(D_{\text {rod }} \approx 0.23\right.$ inch) so as to maintain a reasonably uniform mixture of both fuel and poison in the rotary dissolver. Any large dichotomy would, of course. cause one or the other constituents to preferentially "settle out" on the bottom of the dissolver drum, thus violating the underlying assumption of a uniform mixture upon which this entire analysis is based." With a desire to make the $\mathrm{B}_{4} \mathrm{C}$ pellets as small as possibie, subject to these constraints, it was then assimed for calculational purposes that the steel-clad $\mathrm{B}_{\mathbf{4}} \mathrm{C}$ pellets would have an outside diameter of 0.25 inches. [Thus, from the viewpoint of maintaining a uniform mixture of fuel and poison, this might be considered the smallest recommended value, whilc, dui to the spatial-self-shielding effects previously described, it might also be considered the largest recommended value. In short, the outside diameter of the $\mathrm{B}_{4} \mathrm{C}$ pellets is fairly well constrained.]

At first glance, it would appear that one could still vary the amount of $\mathrm{B}_{4} \mathrm{C}$ in the steel-clad pellet and the amount of fuel $\left(\mathrm{MO}_{2}\right)$ in the system. Obviously (for a steel-clad pellet of a given size), the greater the amount of $B_{4} C$ in the pellet, the more fuel $\left(V F_{f}\right)$ one could safely have in the system. The desire, therefore, was to perform the next series of calculations with as much $\mathrm{B}_{4} \mathrm{C}$ as realistically possible inside the steel-clad pellet. Assuming that the stainless-steel cladding on the 0.25 -inch diameter $\mathrm{B}_{4} \mathrm{C}$ pellet should be $\sim 0.016$ inches thick, one would obtain

$$
\operatorname{VF}_{b}(\max )=\operatorname{Vol}\left(B_{4} C\right) /\left[\operatorname{Vol}\left(B_{4} C\right)+\operatorname{Vol}(S S)\right]=\left(\frac{0.125-0.016}{0.125}\right)^{3}=0.663
$$

\footnotetext{
-As noted previously, this is a major assumption, and probably a fairly poor one. Given the lack of a good physical model, however, it is perhaps the best that can be done. While more conservative models could be formulated, one must then ask: What is realistic? Can the spatial distribution be known with any certainty? Is the "worst case model" sufficiently conservative? Indeed, if this control concept were to be pursued further (and there are no definitive plans to do so at this time). then questions such as these, relating to the final mechanical design, the chemical dissolution rates, and the possible stratification of particulate matter in solution, would have to be addressed in more detail.
} 
This would then be the maximum amount of $\mathrm{B}_{4} \mathrm{C}$ that one could realistically have in a 0.25 -inch diameter pellet. In practice, however, the steel from the cladding hulls should also be accounted for, and this would further reduce the maximum value of $V F_{b}$ that should be used in the calculational model. As shown in Appendix $D$, a more realistic value for $\mathrm{VF}_{\mathrm{b}}(\max )$ is $\mathbf{0 . 5 0 \text { . Recognizing }}$ these physical limits and the desire to keep $V F_{b}$ as high as possible, it was assumed that $V F_{b}=$ $V F_{b}(\max )=0.50$.

\section{V.B. DETERMINING LIMITS ON THE RELATIVE AMOUNT OF FUEL ALLOWED IN THE SYSTEM}

With the outside diameter of the $\mathrm{B}_{4} \mathrm{C}$ pellet and the amount of $\mathrm{B}_{4} \mathrm{C}$ in the pellet $\left(\mathrm{VF}_{\mathrm{b}}\right)$ both

fairly well constrained, the next obvious question was: "What is the maximum amount of fuel (VF) that one could have in the system while still ensuring that it remains safely subcritical at all H/Pu ratios?" To answer that question, four distinct series of calculations $\left[\left(a^{\prime \prime}\right),\left(q^{\prime \prime}\right),\left(b^{\prime \prime}\right),\left(c^{\prime \prime}\right)\right]$ were performed using the one-dimensional CSAS 1 model previously described:

$$
\begin{aligned}
& \text { Case }\left(a^{\prime \prime}\right): V F_{f}=0.30, V F_{b}=0.50 \\
& \text { Case }\left(q^{\prime \prime}\right): V F_{f}=0.34, V F_{b}=0.50 \\
& \text { Case }\left(b^{\prime \prime}\right): V F_{f}=0.40, V F_{b}=0.50 \\
& \text { Case }\left(c^{\prime \prime}\right): V F_{f}=0.49, V F_{b}=0.50
\end{aligned}
$$

In each case, the outside diameter of the steel-elad pellet in the calculational model was assumed to be 0.25 inches. [With $V F_{b}=0.50$, the inner diameter was effectively fixed at 0.19843 inches.] The outer radius of the unit cell in the dry system $\left(r_{3 D}\right)$ could then be calculated as

$$
r_{3 D}=r_{2}\left(1-V F_{f}\right)^{-h} \text {, }
$$

and the outer radius of the homogenized fuel/water zone $\left(r_{3}\right)$ for a similar unit cell in a wet system could be determined for any H/Pu ratio, given the data in Table 1. [Indeed, the automated procedure used for generating the actual CSASI input is listed in Appendix C.] Based on previous experience, $\mathrm{H} / \mathrm{Pu}$ ratios between 50 and 10,000 were included in each series of calculations $\left[\left(\mathrm{a}^{\prime \prime}\right),\left(\mathrm{q}^{\prime \prime}\right)\right.$, $\left.\left(b^{\prime \prime}\right),\left(c^{\prime \prime}\right)\right]$, the results of which are summarized in Table 6 and Fig. 4. Chronologically, cases (a") and $\left(c^{\prime \prime}\right)$ were first found to have maximum neutron multiplication factors $\left(k_{\infty}\right)$ of 0.882 and 1.146 , respeciively. Case ( $\left.b^{\prime \prime}\right)$ was then found to have a maximum neutron multiplication factor of 1.036 . Finally, case $\left(q^{\prime \prime}\right)$ was found to have a maximum neutron muitiplication factor of 0.948 . Since this last case appeared to be safely subcritical, the study was then extended to include all $\mathrm{H} / \mathrm{Pu}$ ratios between 0 and 10,000. The more complete results for case ( $\left.q^{\prime \prime}\right)$ are shown in Table 7 and Fig. 5. While the dry system has a neutron multiplication factor $\left(k_{\infty}\right)$ of $9.666, k_{\infty}$ first decreases to a value of 0.408 as the $\mathrm{H} / \mathrm{Pu}$ ratio is raised to $\sim 30$, and then increases to a maximum value of 0.948 near an $\mathrm{H} / \mathrm{Pu}$ ratio of 1000 , after which it then decreases monotonically. Based on these results, case $\left(q^{\prime \prime}\right)$ appears to be safely subcritical at all $\mathbf{H} / \mathrm{Pu}$ ratios.

\section{V.C. A PHYSICAL INTERPRETATION OF THE CALCULATIONAL MODEL}

Before proceeding with additional analyses, it might be well to review the calculational model designated as case $\left(q^{\prime \prime}\right)$ and relate it to the physical model. In the calculational model, $r_{1}=0.09921$ inches, $r_{2}=0.125$ inches, and $r_{3 D}=0.14357$ inches. In the physical model, the inner radius of the steel-clad $B_{4} C$ pellet is given by $r_{i}=r_{1}=0.09921$ inches. Physically, however, the outer radius of the steel-clad $B_{4} C$ pellet $\left(r_{0}\right)$ is actually somewhat less than $r_{2}$ since the volume given by $V=4 \pi\left(r_{2}{ }^{3}-r_{1}{ }^{3}\right) / 3$ in the calculational model also includes the stainless steel associated with the spent fuel cladding hulls. $\mathrm{C}^{\cdot}$ in that the cylindrical FFTF fuel has an outside clad diameter of $0.584 \mathrm{~cm}$, an inside clad diameter of $0.508 \mathrm{~cm}$, and an outer fuel pellet diameter of $0.494 \mathrm{~cm}$, one can write

$$
\operatorname{Vol}(\text { steel in fuel clad })=(0.340) \mathrm{Vol}\left(\mathrm{MO}_{2}\right)
$$


Table 6. Neutron Multiplication Factor $\left(k_{\infty}\right)$ as a Function of the H/Pu Ratio for Several Systems in Which 0.25-inch-Diameter Steel-Clad $\mathrm{B}_{4} \mathrm{C}$ Pellets are Uniformly Dispersed in a Homogeneous Mixture of Fuel and Water.

\begin{tabular}{|c|c|c|c|c|}
\hline $\mathbf{H} / \mathbf{P u}$ & $\begin{array}{c}\text { Case (a") } \\
V F_{f}=0.30 \\
V F_{b}=0.50\end{array}$ & $\begin{array}{c}\text { Case }\left(q^{\prime \prime}\right) \\
V F_{\mathrm{f}}=0.34 \\
V F_{b}=0.50\end{array}$ & $\begin{array}{r}\text { Case (b") } \\
V F_{f}=0.40 \\
V F_{b}=0.50\end{array}$ & $\begin{array}{r}\text { Case }\left(c^{\prime \prime}\right) \\
V F_{f}=0.49 \\
V F_{b}=0.50\end{array}$ \\
\hline $5.00 \mathrm{E}+01$ & 0.373271 & 0.429227 & 0.515997 & 0.650043 \\
\hline $7.00 E+01$ & 0.406327 & 0.470607 & 0.568140 & 0.713420 \\
\hline $1.00 E+02$ & 0.463160 & 0.536398 & 0.644069 & 0.797328 \\
\hline $1.45 E+02$ & 0.542495 & 0.623049 & 0.737457 & 0.892626 \\
\hline $2.00 \mathrm{E}+02$ & 0.620418 & 0.704629 & 0.820732 & 0.973269 \\
\hline $2.50 E+02$ & 0.675364 & 0.760213 & 0.875624 & 1.024170 \\
\hline $3.00 \mathrm{E}+02$ & 0.718386 & 0.803110 & 0.916717 & 1.060840 \\
\hline $4.00 E+02$ & 0.780137 & 0.862768 & 0.971814 & 1.107450 \\
\hline $5.00 E+02$ & 0.820047 & 0.899920 & 1.004120 & 1.132090 \\
\hline $6.00 E+02$ & 0.846115 & 0.923093 & 1.022670 & 1.143910 \\
\hline $8.00 E+02$ & 0.873522 & 0.944868 & 1.035980 & 1.145590 \\
\hline $1.00 E+03$ & 0.882038 & 0.948140 & 1.032100 & 1.131970 \\
\hline $1.20 E+03$ & 0.880200 & 0.941782 & 1.019290 & 1.110950 \\
\hline $1.40 E+03$ & 0.872492 & 0.929892 & 1.001830 & 1.086240 \\
\hline $1.60 E+03$ & 0.861290 & 0.914881 & 0.981818 & 1.060030 \\
\hline $1.80 E+03$ & 0.847874 & 0.898146 & 0.960616 & 1.033200 \\
\hline $2.00 E+03$ & 0.833258 & 0.880475 & 0.938918 & 1.006570 \\
\hline $2.40 E+03$ & 0.802426 & 0.844344 & 0.895914 & 0.955043 \\
\hline $3.00 E+03$ & 0.756079 & 0.791538 & 0.834859 & 0.884011 \\
\hline $3.70 \mathrm{E}+03$ & 0.705293 & 0.735004 & 0.770923 & 0.811378 \\
\hline $4.60 E+03$ & 0.647050 & 0.671196 & 0.700144 & 0.732464 \\
\hline $5.60 E+03$ & 0.591344 & 0.610969 & 0.634324 & 0.660195 \\
\hline $7.00 E+03$ & 0.526733 & 0.541869 & 0.559774 & 0.579417 \\
\hline $8.50 E+03$ & 0.470988 & 0.482845 & 0.496774 & 0.511959 \\
\hline $1.00 E+04$ & 0.425560 & 0.435086 & 0.446233 & 0.458320 \\
\hline
\end{tabular}

Note: $\quad V_{f_{f}}=\operatorname{Vol}\left(\mathrm{MO}_{2}\right) /\left[\operatorname{Vol}\left(\mathrm{MO}_{2}\right)+\operatorname{Vol}\left(\mathrm{B}_{4} \mathrm{C}\right)+\operatorname{Vol}(\mathrm{SS})\right]$ $V F_{b}=\operatorname{Vol}\left(B_{4} C\right) /\left[\operatorname{Vol}\left(B_{4} C\right)+\operatorname{Vol}(S S)\right]$ 


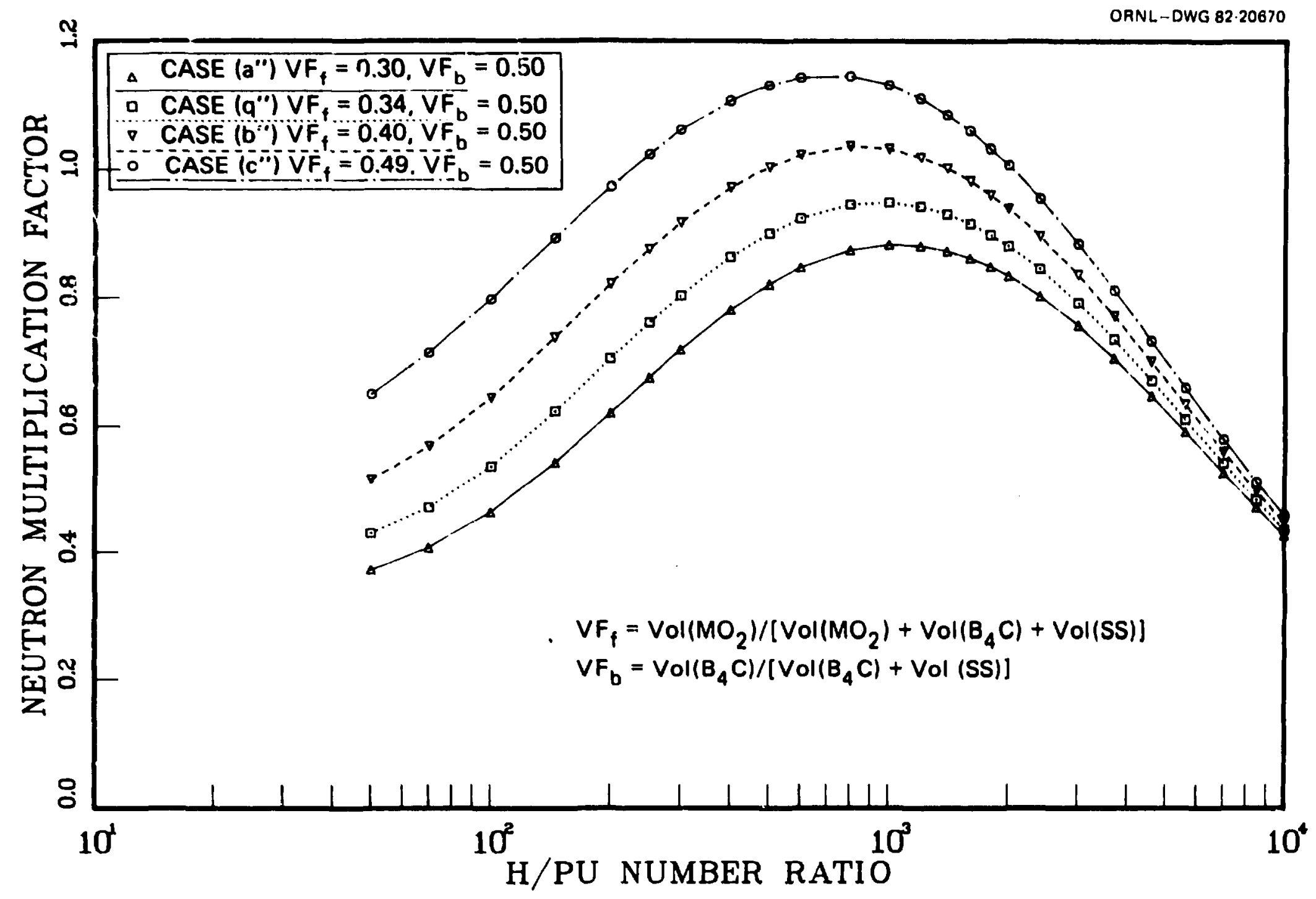

Fig. 4. Neutron Mult,plication Factor $\left(k_{\infty}\right)$ as a Function of the $\mathrm{H} / \mathrm{Pu}$ Ratio for Several Systems in Which 0.25-inch-Diameter Steel-Clad B,C Pellets are Uniformly Dispersed in a Homogenized Mixture of Fuel and Water. 
Table $:$. Neutron Multiplication Factor $\left(k_{\infty}\right)$ as a Function of the $H / P u$ Ratio for a Safely Subcritical System in Which 0.25-inch-Diameter Steel-Clad B4C Pellets are Uniformly Dispersed in a Homogeneous Mixture of Fuel and Water $\left(V_{i}=0.34, V F_{b}=0.50\right)$.

\begin{tabular}{|c|c|c|c|}
\hline $\mathbf{H} / \mathbf{P u}$ & $\begin{array}{l}\text { Case }\left(q^{\prime \prime \prime}\right) \\
V F_{i}=0.34 \\
V F_{b}=0.50\end{array}$ & $\mathbf{H} / \mathbf{P u}$ & $\begin{array}{l}\text { Case }\left(q^{\prime \prime}\right) \\
V F_{f}=0.34 \\
V F_{b}=0.50\end{array}$ \\
\hline I.00E-03 & 0.666259 & $2.5 \cap E: \hat{G} \bar{L}$ & 0.760213 \\
\hline $3.50 \mathrm{E}-02$ & 0.664074 & $3.00 E+02$ & 0.803110 \\
\hline $1.00 \mathrm{E}-01$ & 0.660105 & $4.00 E+02$ & 0.862768 \\
\hline 2.10E-01 & 0.653613 & $5.00 \mathrm{E}+02$ & 0.899920 \\
\hline 4.00E-01 & 0.643020 & $6.00 \mathrm{E}+02$ & 0.923093 \\
\hline $6.50 \mathrm{E}-01$ & 0.630168 & $8.00 E+02$ & 0.944868 \\
\hline $1.00 E+00$ & 0.613920 & $1.00 E+03$ & 0.948140 \\
\hline $1.45 E+00$ & 0.595612 & $1.20 \mathrm{E}+03$ & 0.941782 \\
\hline $2.00 E+00$ & 0.576333 & $1.40 E+03$ & 0.929892 \\
\hline $3.50 \mathrm{E}+00$ & 0.536028 & $1.60 E+03$ & 0.914881 \\
\hline $6.00 E+00$ & 0.492358 & $1.80 E+03$ & 0.898146 \\
\hline $9.50 \mathrm{E}+00$ & 0.455860 & $2.00 \mathrm{E}+03$ & 0.880475 \\
\hline $1.50 E+01$ & 0.425170 & $2.40 \mathrm{E}+03$ & 0.844344 \\
\hline $2.30 \mathrm{E}+01$ & 0.407512 & $3.00 \mathrm{E}+03$ & 0.791588 \\
\hline $3.50 E+01$ & 0.408270 & $3.70 \mathrm{E}+03$ & 0.735004 \\
\hline $5.00 E+01$ & 0.429227 & $4.60 \mathrm{E}+03$ & 0.671196 \\
\hline $7.00 \mathrm{E}+01$ & 0.470607 & $5.60 \mathrm{E}+03$ & 0.610969 \\
\hline $1.00 \mathrm{E}+02$ & 0.536398 & $7.00 \mathrm{E}+03$ & 0.541869 \\
\hline $1.45 E+02$ & 0.523049 & $8.50 \mathrm{E}+03$ & 0.482845 \\
\hline $2.00 \mathrm{E}+02$ & 0.704629 & $1.00 \mathrm{E}+04$ & 0.435086 \\
\hline
\end{tabular}

Note: $\quad \mathrm{VF}_{\mathrm{f}}=\operatorname{Vol}\left(\mathrm{MO}_{2}\right) /\left[\operatorname{Vol}\left(\mathrm{MO}_{2}\right)+\operatorname{Vol}\left(\mathrm{B}_{4} \mathrm{C}\right)+\operatorname{Vol}(\mathrm{SS})\right]$ $V F_{b}=\operatorname{Vol}\left(B_{4} C\right) /\left[\operatorname{Vol}\left(B_{4} C\right)+\operatorname{Vol}(S S)\right]$ 


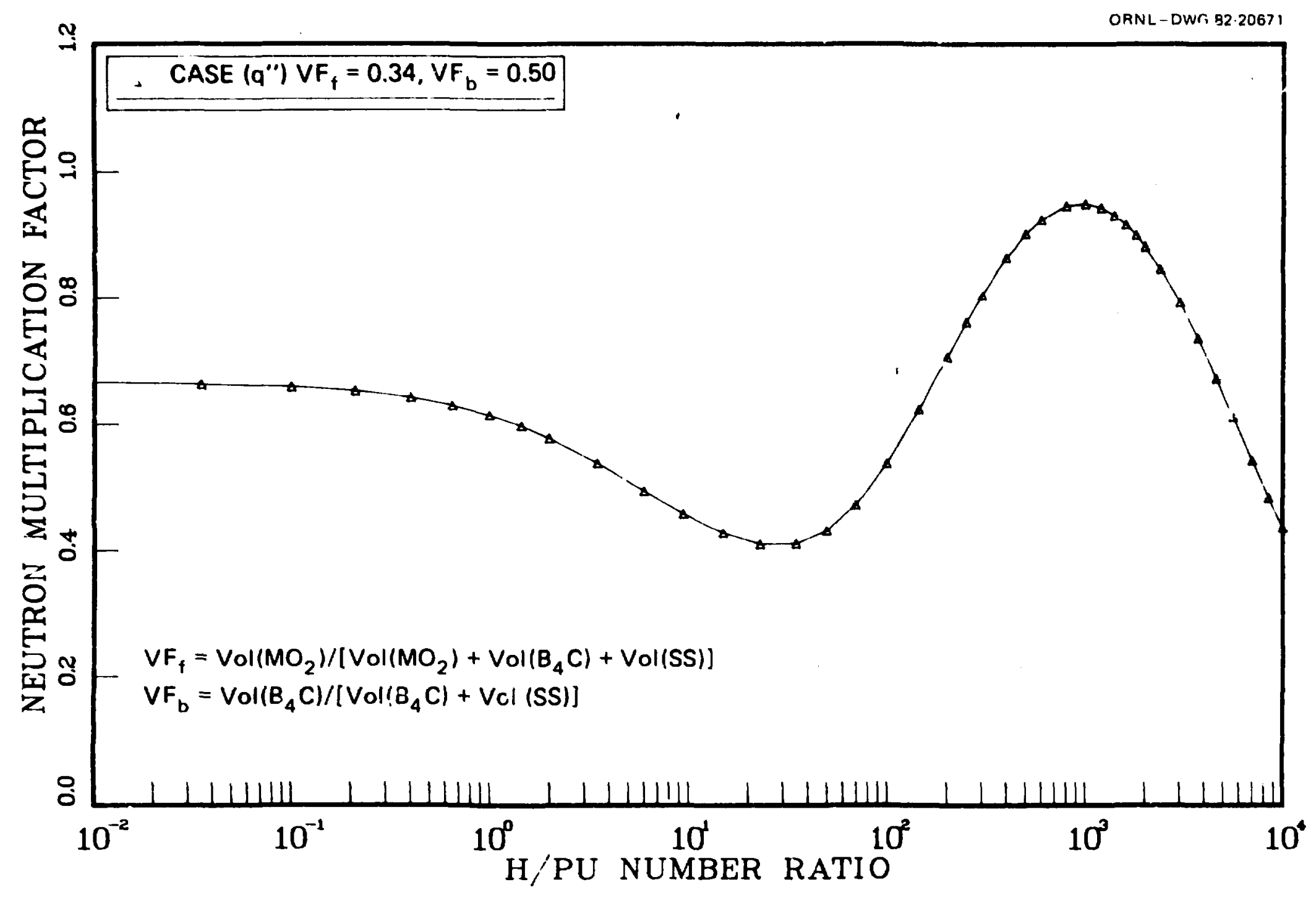

Fig. 5. Neutron Multiplication Factor $\left(k_{\infty}\right)$ as a Function of the F:/Pu Ratio for a Safely Subcritical System in Which 0.25-inch-Diameter Steel-Clad $B_{4} C$ Pellets are Uniformly Dispersed in a Homogenized Mixture of Fuel and Water $\left(\mathrm{VF}_{\mathrm{f}}=0.34\right.$ and $\left.\mathrm{VF}_{\mathrm{b}}=0.50\right)$. 


$$
25 / 26
$$

where

$$
\operatorname{Vol}\left(\mathrm{MO}_{2}\right)=4 \pi\left(\mathrm{r}_{3 \mathrm{D}^{3}} \mathrm{-r}_{2}{ }^{3}\right) / 3=0.004215 \text { in. }^{3}
$$

such that

$$
\text { Vol(steel in fuel clad })=0.001433 \text { in. }^{3} \text {. }
$$

Now, since

$$
\left.4 \pi\left(r_{2}^{3}-r_{0}^{3}\right) / 3=\text { Vol(steel in fuel clad }\right)=0.001433 \text { in. }{ }^{3} .
$$

the real outside radius of the $B_{4} C$ pellet $\left(r_{0}\right)$ is 0.11723 inches $(O D=0.234$ inches). The cladding on the $\mathrm{B}_{4} \mathrm{C}$ pellet would therefore be -18 mils thick, which is not unreasonable. (By comparison, the outside diameter of an FFTF fuel rod is $\sim 0.230$ inches, and its ciadding is $\sim 15$ mils thick). By using $r_{2}$ rather than :- in the calculational model, it effectively accounts for the parasitic absorption by the cladding hulls which would normally be present in the system. 


\section{MULTIDIMENSIONAL ANALYSIS INCLUDING RESONANCE-SELF-SHIELDING EFFECTS IN THE FUEL LUMP(S) AND SPATIAL-SELF-SHIELDING EFFECTS IN THE BAC PELLET(S)}

The one-dimensional CSASI calculations reported in the previous section have shown that 0.25 -inch-diameter steel-clad $\mathrm{B}_{4} \mathrm{C}$ pellets dispersed uniformly in a homogeneous mixture of fuel ar.d water would be sufficient to guarantee subcriticality of the infinite system ai all $\mathrm{H} / \mathrm{Pu}$ ratios provided the corresponding dry system contained no more than $34 \% \mathrm{MO}_{2}$ (iny volume). This constraint is imposed by the fact that the most reactive system has a neutron mutuplication factor of $\sim 0.95$ when the system is optimally moderated and has an $\mathrm{H} / \mathrm{Pu}$ ratio of $\sim 10 \mathrm{CO}$. The fact that the peak in the $k_{\infty}$ vs $\mathrm{H} / \mathrm{Pu}$ curve is so pronounced is due primarily to the spatial-self-shielding within the steel-clad $\mathrm{B}_{4} \mathrm{C}$ pellet(s). (Recall, for example, that the results for the zero-dimensional humogenized models shown in Fig. I did not show the "peak" to be nearly as pronounced)! The existence of this peak, however, is due to the resonance-self-shielding of the fuel in the homogenized fuel/water mixture.

While a system with the fuel and water represented as a homogenized mixture is certainly of interest to the extent that it corresponds to a realistic physical situation in which the fuel is completely dissolved, there are other equally important situations in which the fuel is not dissolved at all, or perhaps onl; partially dissolved. Because the resonance-self-shielded multigroup data for the fuel dzpends on the size of the fuel lump (as well as the amount of water in the system), the current analysis must be extended a step further to determine what, if any, impact the larger fuel lumps would have on the conclusions generated thus far. Obviously, the larger fuel lumps will be more heavily shielded, resulting in lower multigroup values for $\nu \sigma^{8}$ and $\sigma_{2}{ }^{8}$. In low-enriched $\mathrm{UO}_{2}$ systems, the corresponding reduction in parasitic absorption by the ${ }^{238} \mathrm{U}$ will generally dominate and cause the reactivity of the system to increase as the fuel lump becomes larger. In $\mathrm{PuO}_{2}$ systems, however, the ${ }^{239} \mathrm{Pu}$ and ${ }^{241} \mathrm{Pu}$ nuclides have a number of thermal and epithermal fission resonances, and the corresponding reduction in $\nu \sigma_{\beta}^{\beta}$ will generally cause the reactivity of the system to decrease as the fuel lumps become larger. Given that FFTF fuel is a mixed oxide, the overall net effect on the neutron multiplication factor was not obvious.

\section{VI.A. DESCRIPTION OF THE 3-D CALCULATIONAL MODEL, AND THE NECESSARY MODIFICATIONS TO KEIVO-IV}

To assess these effects, one must realistically model trie fuel lump in the resonauce-self-shielding calculation and in the subsequent multigroup transport calculation. At the same time, however, one must also account for the spatial-self-shielding of the boron by explicitly representing the steel-clad $\mathrm{B}_{4} \mathrm{C}$ pellet in the same multigroup transport calculation. The necessity of having to represent both the fuel lumps and the $B_{4} C$ pellets in the same transport calculation obviously precludes the use of one-dimensional codes such as XSDRNPM which is used in the CSAS1 analytical sequence.' Indeed, the small length-to-diameter ratio of the chopped fuel (and/or the $\mathrm{B}_{4} \mathrm{C}$ pcllets if they are not spherical) would also preclude the use of two-dimensional codes such as DOT-IV." To adequately address the problem we therefore decided to use the three-dimensional KENO-IV Monte Carlo code, as incorporated in the CSAS2 analytical sequence provided by the SCALE system. $^{2}$ Within that analytical sequence, the NITAWL code is then used to peiform the

-For a good, albeit elementary, explanation of resonance-self-shielding, the parameters involved, and their various effects, see Appendix C of Ref. 2. 
resonance-self-shielding calculation for the finite fuel lumps surrounded by water in a uniform lattice. In the KENO calculation, a single fuel lump surrounded by water may be defined as box type 1," and a single $\mathrm{B}_{4} \mathrm{C}$ pellet surrounded by water may be defined as box type 2." While the outer dimensions of the two boxes would be identical, they could be varied to obtain the desired $\mathrm{H} / \mathrm{Pu}$ ratio." The infinite system, could then be modeled conceptually by applying reflective boundary conditions on the surface of a large array containing both fuel and poison boxes distributed uniformly in the correct proportions, as determined by VFr and the volume of the individual fuel lumps. In practice, the definition of such an array could be very cumbersome. As an example, assume that the diameter of the fuel lumps and VF, were such that one had an equal number of fuel and poison boxes in the array. One approach would be to place the two boxes [(1) and (2) $\mid$ side by side. Applying reflective boundary conditions to all six sides of the $2 x|x|$ array would then result in a three-dimensional model in which one had two infinite planes containing box type (1). followed by two infinite planes containing box type (2), followed by two infinite planes containing box type (1), followed by two infinite planes containing box type (2), etc. The resulting model would, therefore not be very characteristic of the more-or-:-ss random distribution of fuel lumps and poison pellets in the rotary dissolver. Using a larger, somewhat more complicated, basic array would partially relieve this difficulty, but the construction of such an array would be cumbersome and difficult to defend, and the reflected three-dimensional array would still have some degree of repetitiveness. Indeed, the construction of such an array becomes even more cumbersome when one realizes that the ratio of fuel boxes to poison boxes will depend on the diameter of the fuel lumps if VF, is to be held constant.

In order to avoid the difficulties described above and faithfully represent the uniformly random distribution of materials supposedly more characteristic of the rotary dissolver, some elementary changes were made to the KENO-IV Monte Carlo tracking routines. In addition, a simple unreflected $4 \times 3 \times 3$ array was used, with boxes containing a void (material 0 ) assigned to all array locations except the two innermost ones. Location $(2,2,2)$ was then defined as a fuel box (box type 1), and location $(3,2,2)$ was defined as a poison box (box type 2). While all of the neutrons were obviously started in the fuel, they may eventually be found in both box type 1 and box type 2 . Now, in an infinitely large, uniformly random array of equal size boxes, the probability of a neutron leaving any given box and subsequently entering a fuel box is simply

$$
\mathbf{P}=\mathbf{N}_{\mathrm{l}} /\left(\mathbf{N}_{\mathrm{f}}+\mathbf{N}_{\mathrm{p}}\right)
$$

where $N_{f}$ and $N_{p}$ represent the number of fuel and poison boxes in the large/infinite array. Noting that the volume fraction of the fuel in the dry system (VF, may be written as

$$
V F_{f}=\frac{\left(4 \pi R_{f}^{3} N_{f} / 3\right)}{\left(4 \pi R_{f}^{3} N_{f} / 3\right)+\left(4 \pi R_{2}^{3} N_{p} / 3\right)},
$$

one can determine $\left(N_{p} / N_{1}\right)$, and write a more useful expression for $(l / P)$ :

$$
(I / P)=1+\left(\frac{R_{f}}{R_{2}}\right)^{s}\left[\left(\frac{1}{V F_{f}}\right)-1\right]
$$

where $R_{f}$ is the radius of the (spherical) fuel lump and $R_{2}$ is the radius of the steel-clad $B_{4} C$ pellet in the calculational model (0.125 inches). The KENO-IV tracking algorithm was then modified so that every time a neutron would leave any type of box [(1) or (2)], a random number between 0 and $I$ would be generated and, if less than $P$, the neutron would be assumed to be entering a fuel

\footnotetext{
In the case of very small $\mathrm{H} / \mathrm{Pu}$ ratios, of course, the density of the water had to be numerically set to something less than $1 \mathrm{~g} / \mathrm{cc}$ since the minimum box size had to be big enough to accommodate either the fuel lump or the $\mathrm{B}_{4} \mathrm{C}$ pellet.
} 
box at location $(2,2,2)$ in the array; if the newly generated randon number were greater than $P$. the neutron would be assumed to be entering a poison box at location $(3,2,2)$ in the array. The necessary KENO-IV modifications are shown in Appendix E.

While theoretically sound, the approach described above is somewhat unconventional (as is the problem being solved). To ralidate the approach and verify that the coding changes were properly made. a simple benchmark problem was defined in which identical fuel lumps were placed in box type $I$ and box type 2 . In this !rs! case, all the neutrons were initially started in box type I, P was arbitrarily defined as $\mathbf{0 . 2 0}$, and the resulting fission densities were edited and examined for each box type. After only 2000 histories, the calculated value of $k_{\infty}$ was within half of a standard deviation of that given by the XSDRNPM lattice cell calculation, and, more importantly, 20.33\% of the fissions were found to occur in box type 1, while 79.67\% of the fissions were found to cecur in box type 2. Confident that the new procedure was accurately modeling a uniformly random array, the same approach was then used in the criticality analysis of the rotary dissolver.

\section{VI.B. CRITERIA FOR SELECTING FUEL LIMP SIZES TO BE STUDIED}

One direct result of the resonance-self-shielding calculation performed by NITAWL would be the generation of somewhat lower multigroup cross sections for the uranium and plutonium isotopes in the larger fuel lumps. As noted previously, however, the net overall effect on the neutron multiplication factor was not obvious in advance becaus: of the fundamentally different characteristics of the $\mathrm{UO}_{2}$ and $\mathrm{PuO}_{2}$ in the FFTF fuel. While the limiting case with the fuel completely dissolved was believed to be adequately characterized by the I-D CSASI calculations (cf. Fig. 5), the other cases of interest involving undisiolved or partially dissolved fuel would have to be analyzed using a modified version of the 3-D KENO-IV Monte Carlo code in conjunction with the CSAS2 analytical sequence. Within that analytical sequence, thi resonance-self-shielding calculation is performed by NITAWL with the chopped fuel (or the partially dissolved fuel) being represented as small spherical lumps dispersed throughout the water in a uniform hexagonal lattice. The SUPERDAN routines' ${ }^{5}$ in CSAS2 then use that particular lattice-cell configuration to calculate the appropriate Dancoff factor for use in NITAWL. In addition to the H/Pu ratio, which has a direct impact on the Dancoff factor, the amount of resonance-self-shielding provided by NITAWL is strongly dependent on the size (i.e., the "mean chord length") of the fuel lump. To the extent that the length-to-diameter ratio of the sheared fuel remains reasonably small (i.e., $\leq 5$ ), the idealization of the fuel lump as a sphere will introduce very little error* provided the mean chord length $(4 \mathrm{~V} / \mathrm{S})$ of the spherical model is the same as the mean chord length of the sheared fuel segment. Equating the two terms, the equivalent radius of the sphere $\left(R_{\mathfrak{z}}\right)$ is given by

$$
\frac{3}{R_{s}}=\frac{2}{R_{c}}+\frac{2}{L_{c}} \text {, }
$$

where $R_{c}$ and $L_{c}$ represent the radius and length of the sheared fuel segments. Since some advanced LMFBR fuel designs may have fuel pellets $\sim 0.75 \mathrm{~cm}$ in diameter and the sheared fuel segments may be as long as 2 inches $(5.08 \mathrm{~cm})$, fuel lumps with an equivalent spherical diameter as large as $1.048 \mathrm{~cm}$ should be considered. Noting that FF. $=$ fuel pellets are $-0.494 \mathrm{~cm}$ in diameter and that the fuel shearing device will most likely be used to cut the fuel in 1.inch segments, one might also be interested in fuel lumps with an equivalent spherical diameter of $0.675 \mathrm{~cm}$. Fuel lumps half that size were also of interest to the extent that they would represent partially dissolved fuel. Lastly, the hehavior of very small fuel lumps $\sim 0.1 \mathrm{~cm}$ in diameter were also of interest from an analytical view point. This fine particulate malter suspended in water would be neutronically homogeneous and should, therefore. behave in much the same fashion as the homogeneous

*See Fig. Cl.C.3 of Ref. 2. 
fuel/water mixture previously calculated. In NITAWL, however, slightly different computational algorithms are used for homogeneous mixtures and very small fuel lumps. Beyond that, the unconventional three-dimensional KENO model previously described is significantly different from the simple one-dimensional model provided by XSDRNPM. Comparison of the CSAS2 results for the very small $(0.1-\mathrm{cm}$ diameter) fuel lumps with those from the simple CSASI model would therefore be valuable in validating the current multidimensional approach.

\section{VI.C. THE FINAL ANALYSES}

To summarize, then, there were four cases of particular interest:

Case (z): $D_{\mathbf{f}}=1.00 \mathrm{~cm}-$ largest credible fuel lump

Case (y): $D_{\mathrm{f}}=0.67 \mathrm{~cm}$ - best representation of sheared fFTF fuel

Case (x): $D_{f}=0.33 \mathrm{~cm}$ - partially dissolved fuel

Case (w): $D_{\mathrm{f}}=0.10 \mathrm{~cm}$ - fuel that is aimost completely dissolved or broken up: will also serve as a good cross-check against case ( $\left.q^{\prime \prime}\right)$

In each case $[(w),(x),(y),(z)]$, the discrete fuel lumps were mixed in a uniformly random fashion with the 0.25 -inch-diameter steel-clad $\mathrm{B}_{4} \mathrm{C}$ pellets previously described, while the volume fraction of the fuel in :he dry system $\left(V F_{f}\right)$ was held constant at 0.34 . In each case $[(w),(x),(y),(z)]$, the neutron multiplication factor for the infinite system was then calculated as a function of the $H / P u$ ratio. Tne computerized procedure for generating the necessary CSAS2 input for these calculations is shown in Appendix E. The results from these calculations, along with the results for case ( $\left.q^{\prime \prime}\right)$ representing the steel-clad $B_{4} C$ pellets in a homogenized fuel/water mixture, are summarized in Fig. 6 and Table 8. Note that for undissolved fuel having equivalent lump diameters $\geq 0.5 \mathrm{~cm}$, the dry system represents the most reactive state, with the neutron multiplication factor $\left(k_{\infty}\right)$ being -0.666. As the fuel lumps start to break-up and dissolve, however, the system becomes more reactive, with the maximum value of $k_{\infty}$ occurring at $H / P u$ ratios between 600 and 1000 . From Fig. $\mathrm{h}$, it is obvious that the system is most reactive when the fuel is completely dissolved and the $H / P u$ ratio is $\sim 1000$. At that point, the infinite system is still safely subcritical, with $\mathbf{k}_{o c}=0.948$. The fact that the three-dimensional Monte Carlo results approach the one-dimensional XSDRNPM results as the fuel lumps are made smaller also tends to validate the three-dimensional model used for the larger fuel lumps. 


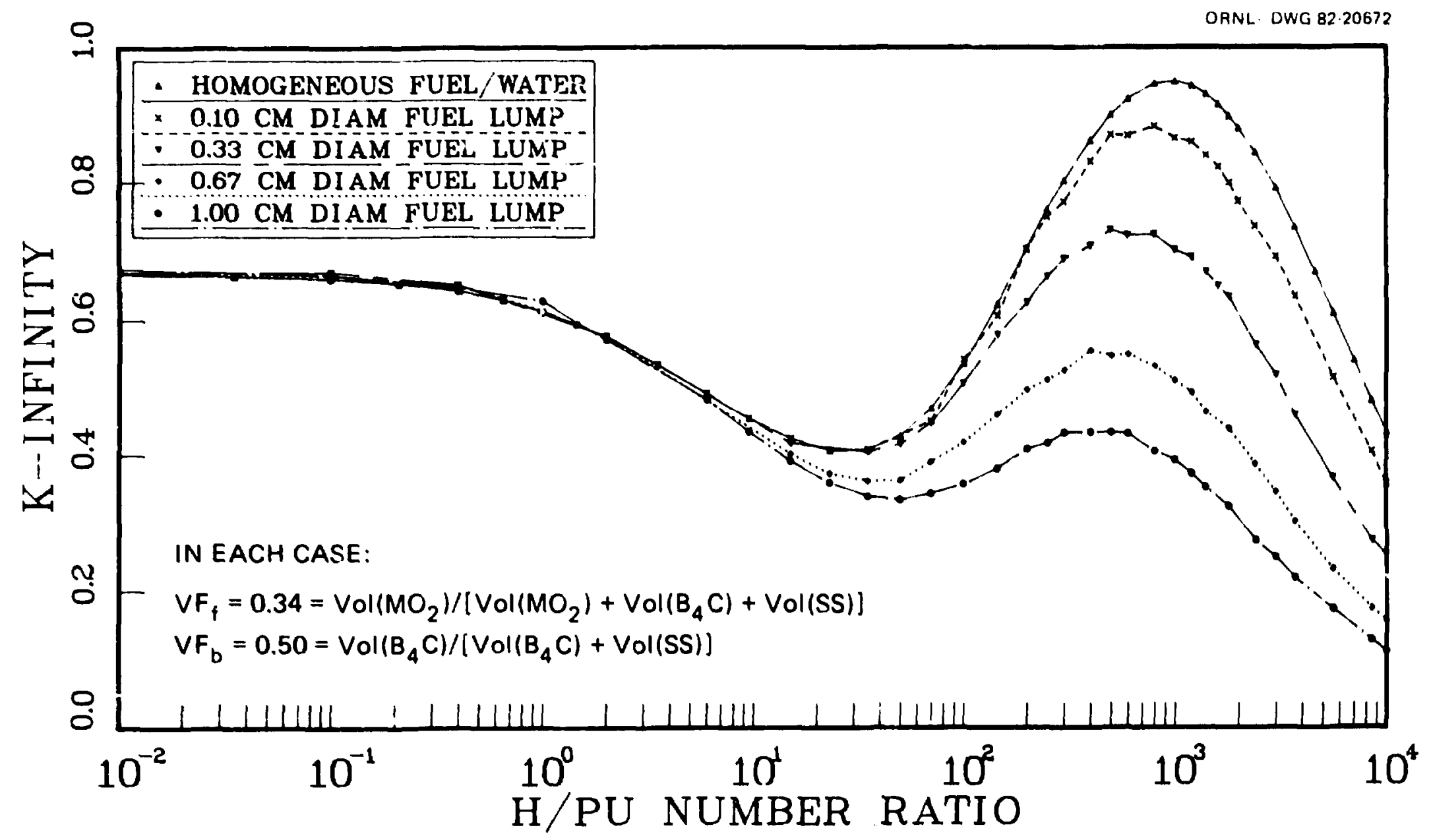

Fig. 6. Neutron Multiplication Factor $\left(k_{\infty}\right)$ as a Function of the H/Pu Ratio for Several Systems in Which 0.25 -inch-Diameter Steel-Clad $B_{4} C$ Pellets are Uniformly Dispersed in a Slurry of Water Containing Discrete Fuel Lumps of a Particular Diameter $\left(D_{r}=1.00 \mathrm{~cm}, 0.67 \mathrm{~cm}, 0.33 \mathrm{~cm}, 0.10 \mathrm{~cm}\right.$, and $0.01 \mathrm{~cm}$ ). 
Table : Neutron Multiplication Factor $\left(k_{x}\right)$ as a Function of the H Pu Ratio for Seceral Sistems in Which 0.:5-inih-Diemeter Steel-Clad $B_{2} C$ Pellets are Liniforml! Dispersed in a Slurn of $\boldsymbol{u}_{\text {ater }}$ Containing Disitete Fuel Lumps of a Particular Diameter $\left(D_{f}=1.00 \mathrm{~cm} .0 .67 \mathrm{~cm} .0 .33 \mathrm{~cm} .0 .10 \mathrm{~cm} \text {. and } 0.01 \mathrm{~cm}\right)^{2 . b . c}$

\begin{tabular}{|c|c|c|c|c|c|}
\hline $\mathbf{H} \mathbf{P u}$ & $\begin{array}{c}\text { Cise }(2) \\
D_{i}=1.00 \mathrm{~cm}\end{array}$ & $\begin{array}{c}\text { Case }(y) \\
D_{i}=0.6^{7} \mathrm{~cm}\end{array}$ & $\begin{array}{c}\text { Case }(x) \\
D_{t}=0.33 \mathrm{~cm}\end{array}$ & $\begin{array}{c}\text { Case }(\mathrm{n}) \\
D_{t}=0.10 \mathrm{~cm}\end{array}$ & $\begin{array}{c}\text { Case }\left(4^{\circ}\right) \\
D_{f}=0.01 \mathrm{~cm}\end{array}$ \\
\hline I.00E-03 & $0.67 t$ & 0.669 & 0.069 & $\cdots \cdot$. & 0.66626 \\
\hline $3.50 \mathrm{E}-02$ & -...- & ..... & $\ldots$ & $\ldots . .$. & $0.6 \times 40^{-}$ \\
\hline $1.00 \mathrm{E}-0 \mid$ & 0.605 & 0665 & $0.6^{70}$ & $\ldots$ & 0.66010 \\
\hline $2.10 \mathrm{E}-0 \mathrm{I}$ & -... & ..... & $\cdots$ & --- & 0.65361 \\
\hline$f .(N O E-01$ & $11.6+8$ & Otoil & 0.652 & ..... & $0.6+30 \hat{U}^{2}$ \\
\hline S.50E-01 & ----- & ..... & ..... & ..... & 0.63017 \\
\hline$(.00 \mathrm{E}-(0)$ & 0.029 & 0615 & 0.611 & $\ldots . .$. & $0.6139 ?$ \\
\hline $1+5 E-(n)$ & -.... & ..... & ..... & ----- & 0.59561 \\
\hline $2.00 E-(X)$ & 0 & 0.5 & 0.578 & ..... & 0.57633 \\
\hline $3.50 \mathrm{E}-(\mathrm{O})$ & ..... & -.... & -...- & -.-. & $0.5360\}$ \\
\hline $0.00 E-(00)$ & $0.4 \times 4$ & $0+x+$ & $0 . \$ 93$ & $\ldots .$. & 0.49236 \\
\hline $9.50 E-00)$ & $0+36$ & ..... & ..... & ..... & $0 . \$ 5586$ \\
\hline $1.50 E-01$ & $0.35 ?$ & C. 40 I & $0: ! 8$ & $\ldots$. & 0.42517 \\
\hline $230 E-01$ & C.361 & 0.174 & ...- & -.... & 0.40751 \\
\hline $3.50 E-01$ & 0.340 & 0.363 & $n .+05$ & 0.409 & 0.40827 \\
\hline $5 . \mathrm{ANE}-01$ & 0.335 & 0.364 & $0 .+17$ & ..... & $0 . \$ 2923$ \\
\hline ?.100E-0I & $0.3+4$ & 0.390 & 0.449 & 0.451 & $0 . \$ 7061$ \\
\hline $1.00 E-02$ & 0.158 & 0.420 & 0.507 & $0.5+3$ & 0.53640 \\
\hline $1.45 E-02$ & $0.3 \times 0$ & 0.462 & 0.580 & 0.607 & 0.62305 \\
\hline $2.00 E-02$ & $11 .+10$ & 0.498 & 0.620 & 0.704 & 0.70463 \\
\hline $250 E+112$ & $0.41 x$ & 0.513 & 0.663 & $0.7+9$ & 0.76021 \\
\hline $300 \mathrm{E}-02$ & 0.434 & $0.5 ?$ & 0.690 & 0.771 & 0.80311 \\
\hline$+.00 E+02$ & 0.435 & 0.556 & 6. 708 & 0.831 & 0.86277 \\
\hline $500 E-02$ & 0.434 & 0.548 & 0.730 & 0.871 & 0.89992 \\
\hline $6.00 E-0 Z$ & $0 .+32$ & 0.550 & 0.722 & 0.870 & $0.0=19$ \\
\hline$\times .0 \mathrm{OE}-02$ & 0.406 & 0.5 .12 & 0.724 & 0.884 & $0.4-4+0 ?$ \\
\hline I. $.0 \mathrm{OE}-03$ & 0.393 & 0.512 & 0.702 & 0.866 & $0.4 \$ 814$ \\
\hline $1.20 \mathrm{E}+03$ & 0.374 & 0.494 & 0.692 & $0.86 \mathrm{I}$ & 0.94178 \\
\hline $1+0 E+0$. & 0.354 & $0 .+65$ & 0.670 & 0.840 & 092989 \\
\hline $1 . \mathrm{AOE}-03$ & ..... & ..... & 0.649 & 0.823 & 0.91488 \\
\hline$(x 0 \mathrm{E}+03$ & 0.325 & $0.4+0$ & 0.633 & 0.800 & 0.89815 \\
\hline $200 \mathrm{O}-0.3$ & ..... & ..... & ..... & 0.772 & 0.88047 \\
\hline $2+0 \mathrm{E}-03$ & $0.2 ? h$ & $0.3 \times 7$ & 0.564 & 0.736 & 0.84434 \\
\hline $3(x) 5-113$ & 0.250 & 0.347 & 0.519 & 0.693 & 0.79159 \\
\hline $370 \mathrm{E}-113$ & 0.220 & $0.30 !$ & 0.461 & 0.634 & 0.73500 \\
\hline $4005:+03$ & $\ldots$ & $\cdots$ & $\ldots .$. & ..... & 0.67120 \\
\hline S. $\mathrm{nOF}:-0,3$ & $0.1 ? 3$ & 0.233 & $0.36 i$ & 0.516 & 0.61097 \\
\hline $7 \mathrm{OOF}+113$ & $\ldots .$. & $\ldots$ & $\ldots .$. & ..... & 0.54187 \\
\hline$\times\{() E-0\}$ & 0.129 & 0.174 & 0.296 & 0.406 & 0.48285 \\
\hline $1 \mathrm{OOF}+04$ & 0.112 & 0.156 & 0.254 & 0.359 & 0.43509 \\
\hline
\end{tabular}

In each casc. the relative volum:* of the fuel and the $B_{4}(\cdot$ was held constant such that

$V F_{1}-0.34=\operatorname{Voll}\left(\mathrm{MO}_{2}\right) /\left[\operatorname{Vol}\left(\mathrm{MO}_{2}\right)+\operatorname{Vol}\left(\mathrm{B}_{4}(\mathrm{C})+\operatorname{Vol}(\mathrm{SS})\right]\right.$

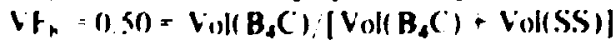

"In cise $\left(4^{\prime \prime}\right)$, an homoginized ruel/water mixlure was used in lieu of discrete fuel lumps. and the quoted results were calculated using the 1-D XSDRNPM code. In all the other cince. a modified version of the a.D KENO.IV Monie Carlo code was used. and the quired results were converged to within \pm 0.004 .

' Besiluse o' the high sust of ohtaining gond statistics. some salculations were intentionally ikinped 


\section{vil. CONCLUSIONS}

Without relying on mass control and/or the use of soluble neutron poisons in solution, one can still make the rotary dissolver safely subcritical through the use of steel-ciad $\mathrm{B}_{4} \mathrm{C}$ pellets mixed uniformly with the undissolved or partially dissolved FFTF fuel. While sniall cylindrically shaped $B_{4} C$ pellets would certainly be possible, the calculations wer= performed assuming the pellets were spherically shaped, with an inside diameter of 0.19842 inchers and an outside diameter of 0.25 inches. If one takes credit for parasitic absorption by the fuel's cladding hulls, then the actual outside diameter of ene steel-clad $\mathrm{B}_{4} \mathrm{C}$ pellets may be reduced to 0.234 inches. To be safely subcritical under all conditions $\left(k_{\infty} \leqslant 0.95\right)$, the system should contain roughly equal volumetric amounts of $\mathrm{B}_{4} \mathrm{C}_{2}$ mixed oxide fuel, and stainless-steel cladding. [Given that an FFTF fuel pellet has an outside diameter of $0.494 \mathrm{~cm}$ and that the FFTF fuel is to be sheared inte 1-inch segments, one must provide approximately seven of the small steel-clad $\mathrm{B}_{4} \mathrm{C}$ pellets for each piece of steel-clad FFTF fuel added to the dissolver.] While dry systems (and/or wet systems with undissolved fuel) will be very subcritical (cf. Fig. 6), these proportions will ensure that the most reactive case (corresponding to completely dissolved fuel at an $\mathrm{H} / \mathrm{Pu}$ ratio of -1000 ) will remain safely subcritical. Increasing the relative amount of fuel in the system would, of course, allow for a potential criticality incident (cf. Fig. 4). Interestingly, the use of somewhat larger $\mathrm{B}_{4} \mathrm{C}$ poison pellets would further restrict the relative amount of fuel $\left(V F_{f}\right)$ that one could have in the system. This seemingly paradoxical effect is, of course, due to the spatial-self-shielding of the boron that would oicur in the larger pellets. The only way to increase the relative amount of fuel in the system would be to use somewhat smaller steel-clad $B_{4} C$ pellets. Unfortunately, as noted in Section V.A, smaller pellets may be difficult to manufacture and would probably lead to a nonuniform spatial distribution of materials in the rotary dissolver.

Underlying this entire analysis is a major assumption that the fuel and the poison pellets are distributed more-or-less uniformly in the rotary dissolver. While this may or may not be a good assumption, it is probably the best that can be done given ite lack of a good physical model describing the spatial distribution of materials in the rotating and/or stationary system. Obviously, more conservative models could be formulated which would preclurle a solution. One must then ask: What is realistic? Can the spatial distribution be known with any certainty? Is the "worst case model" sufficiently conservative? Indeed, if this control cor.cept were to be pursued further (and there are no definitive plans to do so at this time), then qurstions such as these, relating to the final mechanical design, the chemical dissolution rates, and the possible stratification of particulate matter in solution, would have to be addressed in more detail. In addition, questions associated with the operational complexities and the necessary equipment modifications needed to employ this type of control would have to be examined to complete the study. 


\section{REFERENCES}

1. J. A. Bucholz, "SCALE System Criticality Safety Analysis Module CSASI" as described in Section C1 of SCALE: A Modular Code System for Performing Standardized Computer Analyses for Licensing Evaluation, ORNL/NUREG/CSD-2, Vol. 1, Rev. 1 (October 1981).

2. J. A. Bucholz, SCALE System Criticality Safety Analysis Module CSAS2" as described in Section C2 of SCALE: A Modular Code System for Performing Standardized Computer Analyses for Licensing Evaluation. ORNL/NUREG/CSD-2, Vol. 1, Rev. 1 (October 1981).

3. Carpenter Technology, Carpenter Chrome-Nickel Stainless wilh Bcron (Modified Type 304 with Boron). Technical Data Sheet, Carpenter Technology Corporation (February 1980).

4. W. A. Rhoades and R. L. Childs, An Updated Version of the DOT-4 One- and TwoDimensional Neutron/Photon Transport Code, ORNL-5851 (July 1982).

5. J. R. Knight, SUPERDAN: Computer Programs for Calculating the Dancoff Factor of Spheres, Cylinders, and Slabs, ORNL/NUREG/CSD/TM-2 (March 1978). 
APPENDICES 


\section{APPENDIX A \\ AUTOMATED PROCEDURE USED FOR GENERATING THE ACTUAL CSASI INPUT FOR THE CALCULATIONS DESCRIBED IN SECTIOV II}

As noted in Section II, a great many scoping calculations were initially performed for infinite homogeneous systems having various amounts of mixed oxide fuel, boron carbide $\left(\mathrm{B}_{4} \mathrm{C}\right)$, and stainless steel. In the actual analysis, the PDP-10 'MIC' file shown below (B4CSTL.MIC) was used to generate the CSASI input and produce the results shown in Table 2. To illustrate the uility of such an at:tomated procedure. consider the 8 columns of Table 2 as being labeled $A, B$, $C, D, E, F, G$, and $H$. To perform a cal-ulation wherein $V F_{b}=0.15$ and $V F_{f}=0.30$, one would enter

$$
\text { .DO BACSTL.MIC C,30 , }
$$

while to perform a calculation wherein $V F_{b}=0.70$ and $V F_{f}=0.54$, one would enter

$$
\text { .DO B4CSTL.MIC F,54 . }
$$

The PDP-10 will then prepare and submit the necessary CSASI input to the IBM-3033 computer. In the case of column $B\left(\mathrm{VF}_{\mathrm{b}}=0.035\right)$, the $\mathrm{B}_{4} \mathrm{C}$ standard composition specification card was changed to BORON to model a special type of borated stainless steel containing -1.2 wt $\%$ natural boron. 


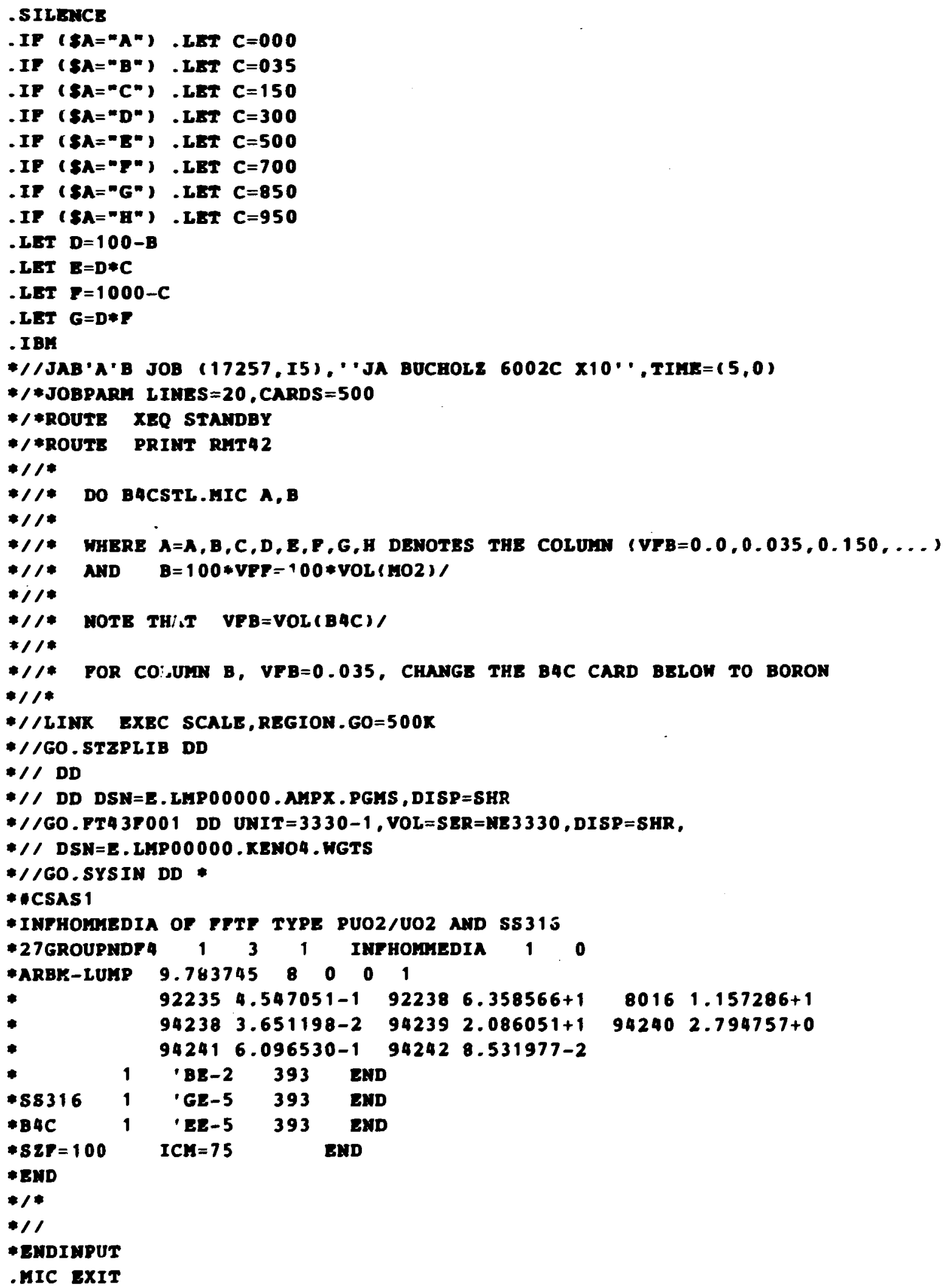




\section{APPENDIX B \\ AUTOMATED PROCEDURE USED FOR GENERATTNG THE ACTUAL CSASI INPUT FOR THE CALCULATIONS DESCRIBED IN SECTION III}

In Section III, the neutron multiplication factor $\left(k_{\infty}\right)$ was determined as a function of the H/Pu ratio for several infinite homogeneous mixtures of mixed oxide, water, boron carbide, and stainless steel. Specifically, three different homogeneous media were examined, with

$$
\begin{aligned}
& \text { Case (a): } V F_{f}=0.30, V F_{b}=0.15 \\
& \text { Case (c): } V F_{f}=0.49, V F_{b}=0.50 \\
& \text { Case (e): } V F_{f}=0.60, V F_{b}=0.95
\end{aligned}
$$

In the actual analysis, the PDP-10 'MIC' file shown below (WETING.MIC) was used to gerreratc the CSASI input and produce the results shown in Table 3. To perform a calculation for case (a) at an $\mathrm{H} / \mathrm{Pu}$ ratio of 3.5 , one would enter

\section{DO WETING.MIC A,35 ,}

while to perform a calculation for case (e) at an H/Pu ratio of 145.0 one wuld enter

\section{.DO WETING.MIC E,I450 .}

Note that the second parameter is an integer which equals ahe $\mathrm{H} / \mathrm{Pu}$ ratio multiplied by a factor of ten. (For $\mathrm{H} / \mathrm{Pu}$ ratios of $0.001,0.035,0.21,0.65$, and 1.45, the second parameter should be the $\mathrm{H} / \mathrm{Pu}$ ratio multiplied by a factor of one thousand, and the line (shown below) reading *'BE-I should be changed to *BE-3. Requiring the second parameter to be an integer will permit it to be incorporated as part of the job name when the CSASI case is submitted to the IBM-3033 computer.) 


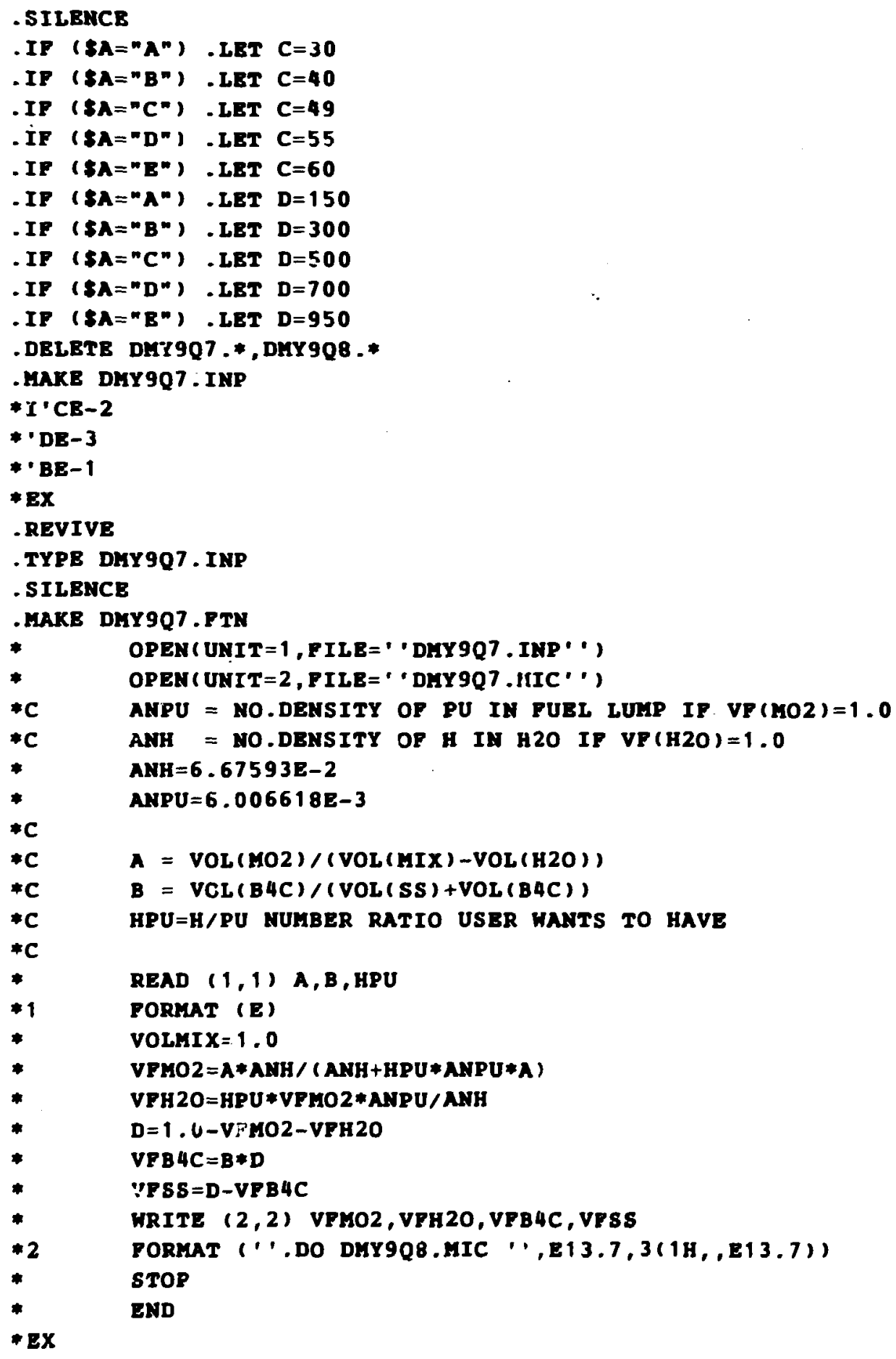




\section{$43 / 144$}

. COMPILE DKY9Q7 . PTN

.BXBCUTB DKY9Q7.REL

.MAKB DHY9Q8. HIC

*I. I BM

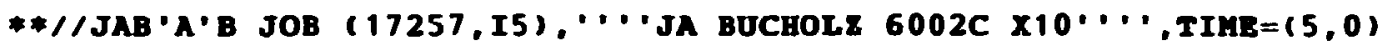

* * / JOBPARA LINES $=20$, CARDS $=500$

* * * ROUTB XEQ STANDBY

* * *ROUTE PRINT RrT42

* */LIMT BXEC SCALE,REgIOH.GO=500K

* //GO. STEPLIB DD

* $/ 1$ DD

* $/ /$ DD DSU=CND10 . JAB 13884 . MIXEHI, DISP=SAR

* * / DD DSH=E . LHP00000 . AHPX. PGHS , DISP=SHR

* *//GO. FT4 3F001 DD UNIT=3330-1, VOL=SER=NE3330, DISP=SHR,

* // DSN=B . LHP0O000 . KBLO4 . WGTS

**//GO.SYSIY DD*

* * Csas 1

* INPHOHEDIA OP PFTP TYPE PU02/U02 AND SS316

* 27GROUPNDF 11441 INFHC:HENTA 1

* *ARBH-LUMP $9.783745 \quad 8 \quad 0 \quad 0 \quad 1$

* $\quad 922354.547051-1922386.358566+1$

$942583.651198-2092392.085051+1$

* $\quad 942416.096530-1 \quad 942428.531977-2$

* 1 " A 393 BND

$*+420 \quad 1 \quad \cdots B \quad 393 \quad$ BND

* * B C 1 " 1 C 393 END

* *SS316 1 'D 393 EN?

* * SZF $=100 \quad$ ICK $=75 \quad$ BND

* *ND

$* * 1 *$

$* * 11$

* *NDINPUT

* EX

.TYPE DMY9Q7.MIC

. DO DHY 9Q7 . MIC

.DELETE DKY9Q7 * , DHY9Q8 . *

- REVIVE

MIC EXIT 


\section{APPENDIX C}

\section{AUTOMATED PROCEDURE USED FOR GENERATING THE ACTUAL CSASI INPUT FOR THE CALCULATIONS DESCRIBED IN SECTIONS IV AND V.B}

Because of spatial self-shielding effects in the $\mathrm{B}_{4} \mathrm{C}_{1}$ it was necessary to perform a great many one-dimensional criticality calculations with the steel-clad $\mathrm{B}_{4} \mathrm{C}$ poison pellet of some. fixed dimension (0.5-inch diameter or 0.25 -inch diameter) surrounded by a fissile mixture of fuel and water. In these calculations, the relative amounts of fuel $\left(V F_{f}\right)$ and $B_{4} C\left(V F_{b}\right)$ may be fixed, and the amount of water in the system (i.e., the $\mathrm{H} / \mathrm{Pu}$ ratio) may assume any credible value $(0<\mathrm{H} / \mathrm{Pu}<10000)$. In Section IV, the steel-clad $\mathrm{B}_{4} \mathrm{C}$ pellet was assumed to have an outside diameter of 0.5 inches $(1.27 \mathrm{~cm}$ ). A series of calculations at various $\mathrm{H} / \mathrm{Pu}$ ratios (cf. Table 4 or Table 5) were then performed for each of five cases, identified as

$$
\begin{array}{lll}
\text { Case (a): } V F_{f}=0.30 & V F_{b}=0.15 \\
\text { Case (a'): } V F_{f}=0.30 & V F_{b}=0.95, \\
\text { Case (c): } V F_{f}=0.49 & V F_{b}=0.50, \\
\text { Case (c): } V F_{f}=0.49 & V F_{b}=0.95, \\
\text { Case (c): } V F_{f}=0.60 \quad V F_{b}=0.95
\end{array}
$$

In Section $V$, the steel-clad $B_{4} C$ pellets were assumed to have an outside diameter of 0.25 inches $(0.635 \mathrm{~cm}$ ), and a series of calculations at various $\mathrm{H} / \mathrm{Pu}$ ratios (cf. Table 6 and Table 7 ) were then performed for each of the four cases identified there as

$$
\begin{aligned}
& \text { Case (a"): } V F_{\mathrm{f}}=0.30 \quad V F_{b}=0.50 \text {, } \\
& \text { Case ( } \left.q^{\prime \prime}\right): V F_{f}=0.34 \quad V F_{b}=0.50 \text {, } \\
& \text { Case }\left(b^{\prime \prime}\right): V F_{f}=0.40 \quad V F_{b}=0.50 \text {, } \\
& \text { Case (c"): } V F_{f}=0.49 \quad V F_{b}=0.50 \text {. }
\end{aligned}
$$

To uniquely ider,tify the output, each series of calculations was assigned a special three-character ID:

\begin{tabular}{|c||c|c|c|c|c|c|c|c|c|}
\hline Series & $(\mathrm{a})$ & $\left(\mathrm{a}^{\prime}\right)$ & $(\mathrm{c})$ & $\left(\mathrm{c}^{\prime}\right)$ & $\mathbf{c}$ & $\mathbf{a}^{\prime \prime}$ & $\mathbf{q}^{\prime \prime}$ & $\mathbf{b}^{\prime \prime}$ & $\mathrm{c}^{\prime \prime}$ \\
\hline ID & AAA & AAE & CCC & CCE & EEE & iSS & QSS & BSS & CSS \\
\hline
\end{tabular}

Each individual calculation in a series was further identified by an integer $I(1 \leqslant 1 \leqslant 40)$ which denotes one of the H/Pu number ratios, HPU(I), in the PDP-10 FORTRAN deck listed below. Indeed, the entire PDP-10 'MIC' file (KEFFID.MIC) used to generate the actual CSASI input for any particular set of calculations is shown below. To perform all $\mathbf{4 0}$ calculations in the series corresponding to case (a), one would only need to enter:

.DO KEFF1D.MIC 0.30,0.15,1.27,AAA,1,40 ,

while to perform the last 25 calculations in the series corresponding to case (b"), ons would only need to enter:

$$
\text { .DO KEFFID.MIC } 0.40,0.50,0.635, B S S, 16,40 \text {. }
$$

Here, the first and second parameters are $V F_{r}$ and $V F_{i r}$ respectively; the third parameter is the outside diameter of the steel-clad $\mathrm{B}_{4} \mathrm{C}$ pellet in centimeters; the fourth parameter is the alphanumeric series ID; and the fifth and sixth parameters (N1 and $\mathrm{N} 2$ ) designate which elements of the series (HPU(I),I $=N 1, N 2)$ are to be submitted. Note that all of the output from sach CSASI calculation is saved on microfiche, and that some of the key results (such as $k_{\infty}$ and some of the convergence parameters) are also saved on punched cards. 


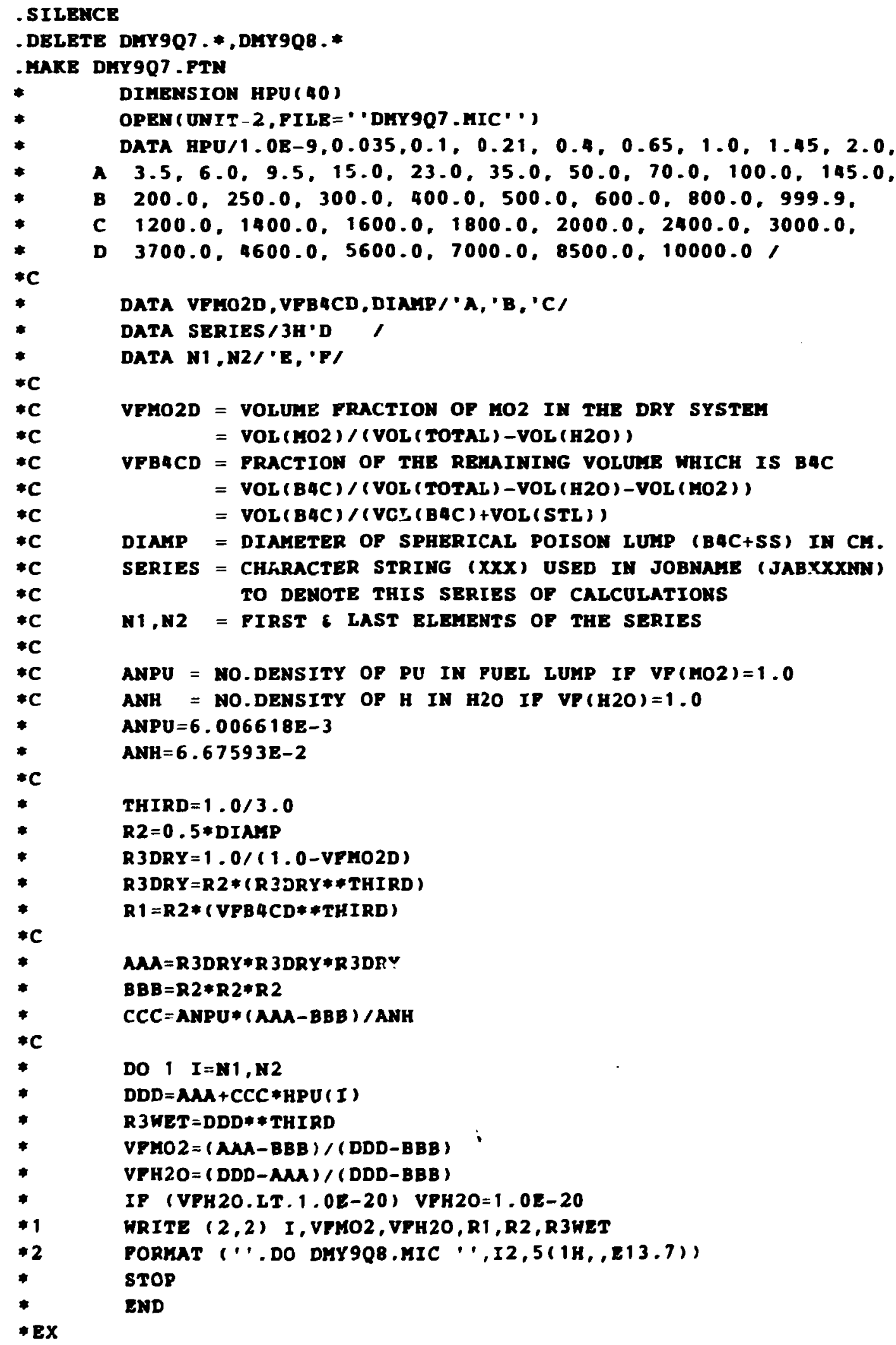




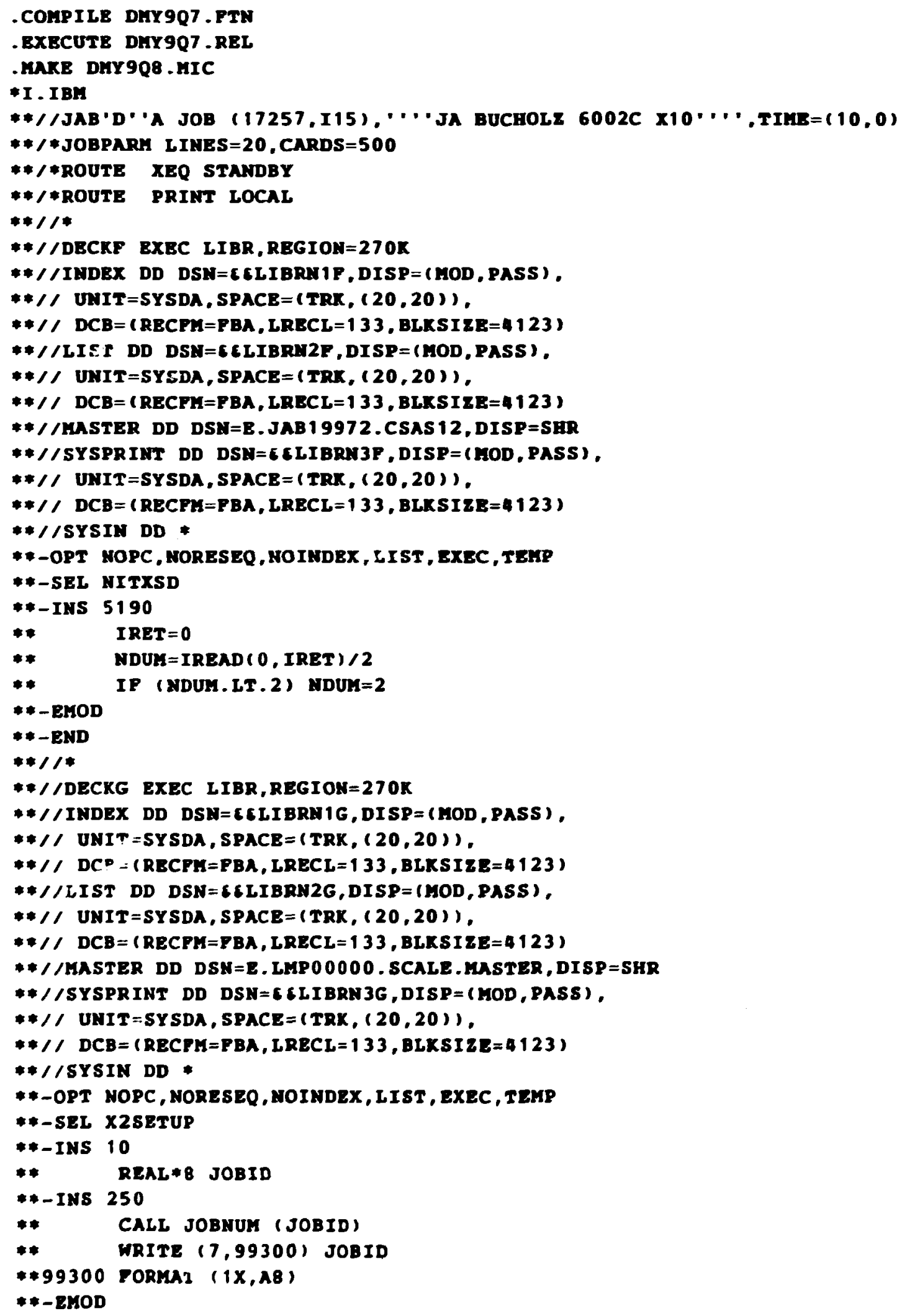




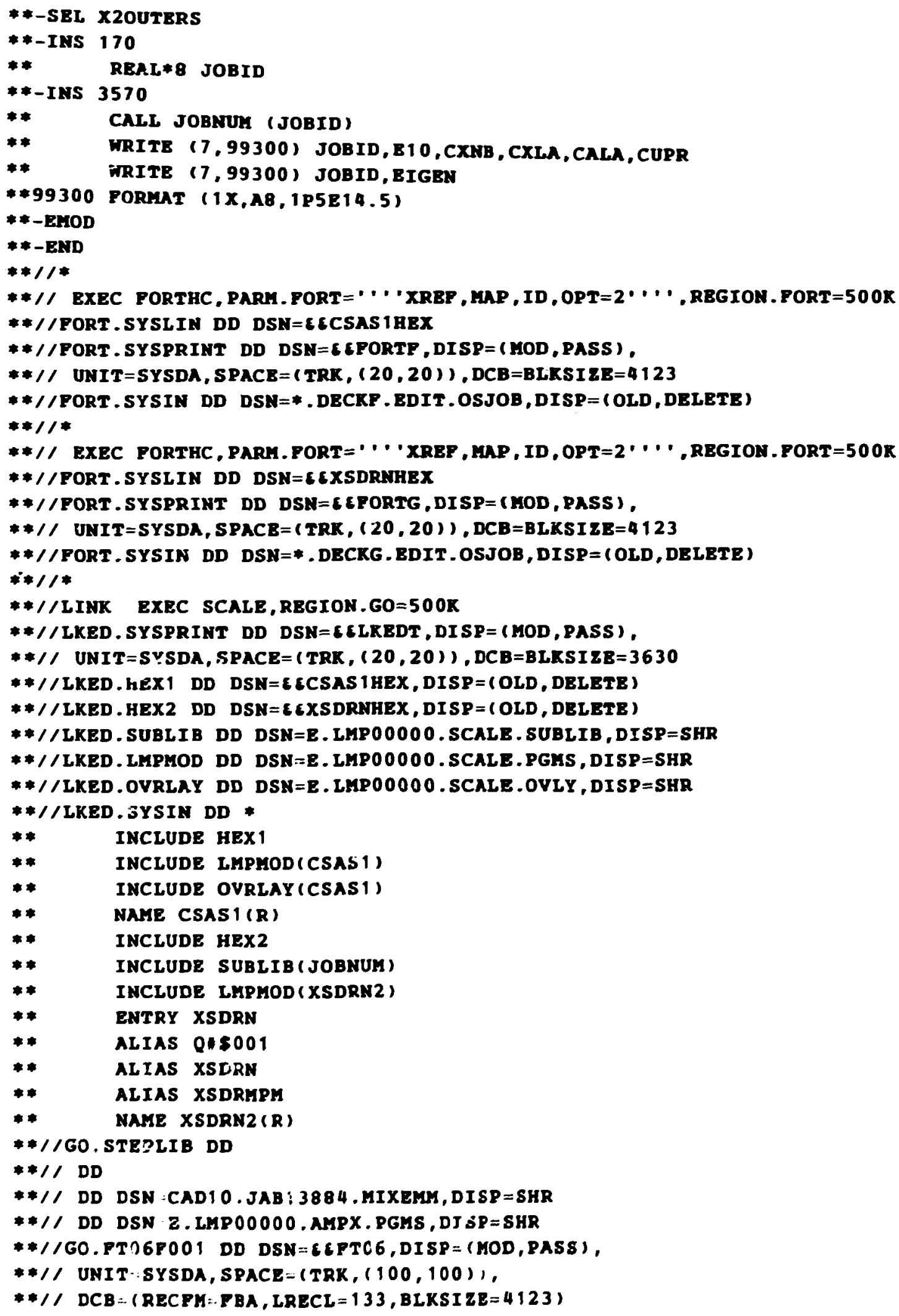




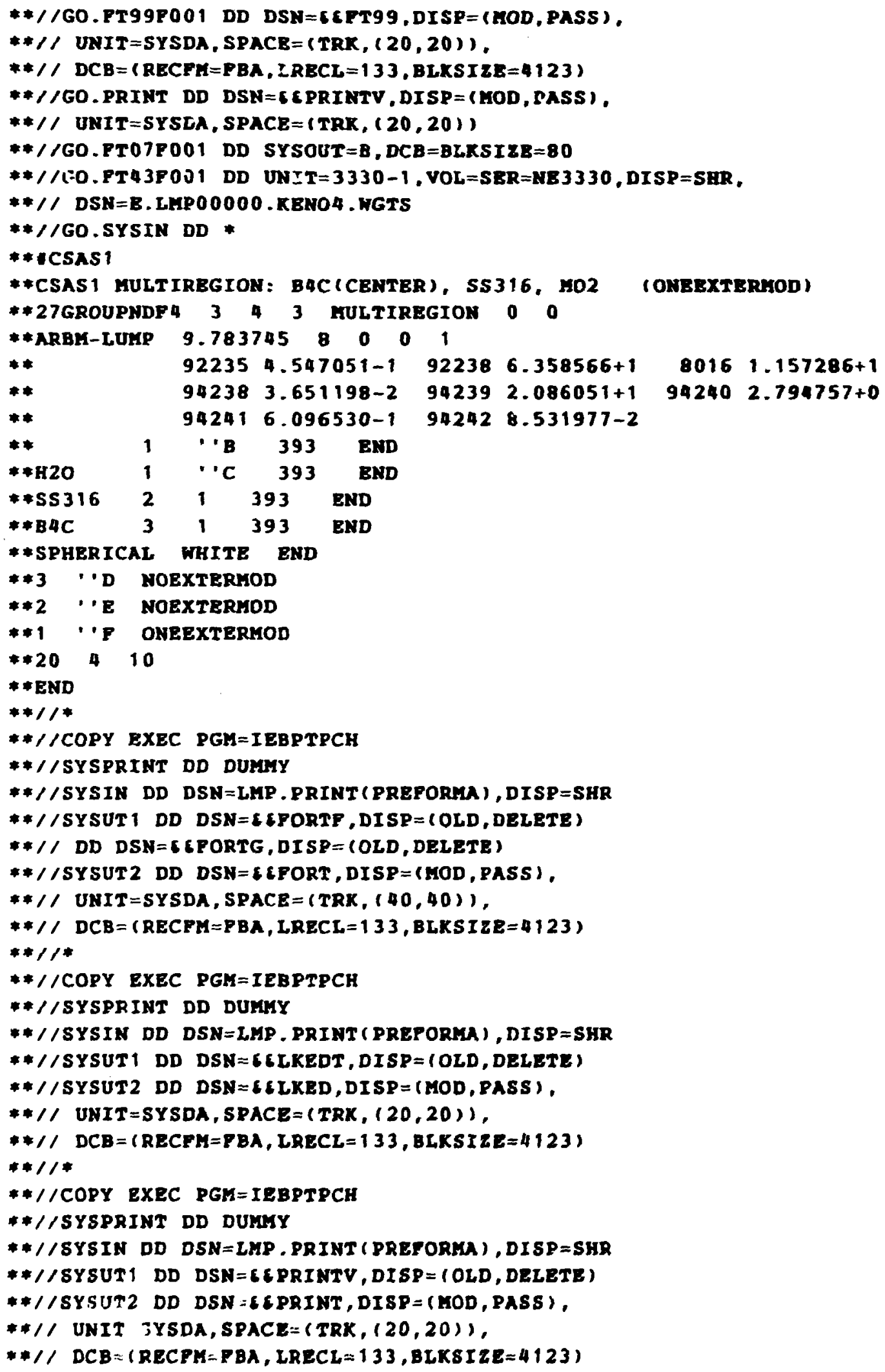




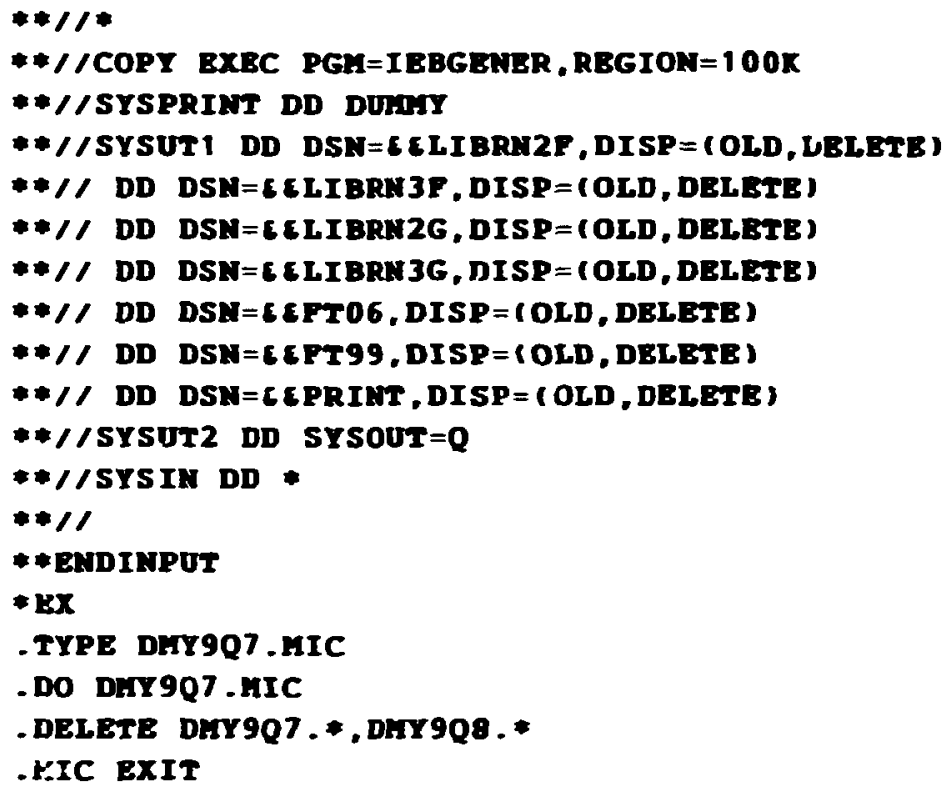




\section{APPENDIX D}

\section{DETERMINATION OF VF, (MAX) FOR SYSTEMS HAVING 0.25-INCH DIAMETER, STEEL-CLAD B,C PELLETS}

Assuming that the stainless-steel cladding on the 0.25 -inch diameter $\mathrm{B}_{4} \mathrm{C}$ pellet should be -0.C16-inches thick, one would obtain

$$
\mathrm{VF}_{\mathrm{b}}(\max )=\operatorname{Vol}\left(\mathrm{B}_{4} \mathrm{C}\right) /\left[\operatorname{Vol}\left(\mathrm{B}_{4} \mathrm{C}\right)+\operatorname{Vol}(\mathrm{SS})\right]=\left[\frac{0.125-0.016}{0.125}\right]^{3}=0.663 . \text { (D.1) }
$$

This would be the maximum amount of $\mathrm{B}_{4} \mathrm{C}$ that one could realistically have in a 0.25 -inch diameter pellet. In practice, however, the steel from the cladding hulls should also be accounted for, and this would further reduce the maximum value of $\mathbf{V F}_{\mathrm{b}}$ that should be used in the calculational model. Assuming some reasonable thickness ( $(t)$ for the actual cladding on the $\mathrm{B}_{4} \mathrm{C}$ pellet, and knowing the amount of steei in the computational model that is really associated with the spent fuel cladding hulls [cf. Eq. (D.3)], one could calculate $V_{F_{b}}$ as a function of $V F_{1}$, where

$$
V F_{\mathrm{I}}=\operatorname{Vol}\left(\mathrm{MO}_{2}\right) /\left[\operatorname{Vol}\left(\mathrm{MO}_{2}\right)+\operatorname{Vol}\left(\mathrm{B}_{4} \mathrm{C}\right)+\operatorname{Vol}(\mathrm{SS})\right]
$$

Alternately, one may calculate the actual thickness of the $\mathrm{B}_{4} \mathrm{C}$ pellet cladding ( $t$ ) as a function of $V F_{r}$ and $V F_{b}$. This latter approach, while seemingly backwards, is perhaps the most enlightening.

Ir the case of FFTF fuel, the outside diameter of the clad is $0.584 \mathrm{~cm}$, the inside diameter of the clad is $0.508 \mathrm{~cm}$, and the outer diameter of the (cylindrical) fuel pellet is $0.494 \mathrm{~cm}$, such that

$$
\text { Vol(steel in fuel clad })=(0.340) \mathrm{Vol}\left(\mathrm{MO}_{2}\right) .
$$

In the spherical model used for computational purposes,

$$
V F_{\mathrm{r}}=1-\left(\frac{r_{2}}{r_{3 D}}\right)^{3} \text { [where } r_{2}=0.125 \text { inches]. }
$$

and

$$
\operatorname{Vol}\left(M O_{2}\right)=\frac{4}{3} \pi\left(r_{3 D}^{3}-r_{2}^{3}\right)=\frac{4}{3} \pi r^{3}\left(\frac{V F_{1}}{1-V F_{f}}\right)
$$

If $r_{0}$ denotes the actual outside radius of the steel-clad $B_{4} C$ pellet, such that the region between $r_{0}$ and $r_{2}$ represents the steel associated with the spent fuel cladding hulls, then Egs. (D.3) and (D.S) may be combined to yield

$$
\frac{4}{3} \pi\left(r^{3}-r_{0}^{3}\right)=\frac{4}{3} \pi r^{3}(0.340)\left(-\frac{V F_{f}}{1-V F_{f}}\right) \text {, }
$$


from which one can calculate $r_{0}$ as

$$
r_{0}=r_{2}\left[1-(0.340)\left(\frac{V F_{f}}{1-V F_{f}}\right]^{1 / 3} .\right.
$$

If $r_{1}$ denotes the inner radius of the steel-clad $B_{4} C$ pellet, and $t$ denotes the actual thickness of the steel cladding on the $\mathrm{B}_{4} \mathrm{C}$ pellet (i.e., not including the steel from the spent fuel cladding hulls), then Eq. (D.1) may be written as

$$
V F_{b}=\left(\frac{r_{1}}{r_{2}}\right)^{3}=\left(\frac{r_{0}-t}{r_{2}}\right)^{3} .
$$

Combining Eqs. (D.7) and (D.8), one can then extract a useful expression for t:

$$
t=r_{2}\left\{\left[1-(0.340)\left(\frac{V F_{1}}{I-V F_{I}}\right)\right]^{1 / 3}-\left(V F_{b}\right)^{1 / 3}\right\} .
$$

Note that if $V F_{\mathrm{I}}=0.0$ and $V F_{\mathrm{b}}=\mathbf{0 . 6 6 3}$, Eq. (D.9) will yield $\mathrm{t}=\mathbf{0 . 0 1 6}$ inches. Obviously, if this is a reasonable value of $t_{\text {, and }} V F_{f}$ is greater than zero, then $V_{F_{b}}$ must be something less than 0.663. Table 9 gives the $B_{4} C$ pellet cladding thickness $(t)$ as a function of $V F_{f}$ and $V F_{b}$. Those cases where $t$ is negative should, of course, be ignored. Likewise, those cases below the solid stepped line should also be ignored since Table 2 shows the corresponding dry systems to be either supercritical or to have neutron multiplication factors $\left(k_{\infty}\right)$ greater than 0.95 . Indeed, if 15-20 mils is a reasonable thickness for the $B_{4} C$ pellet cladding, then $V F_{b}$ should be no greater than 0.5 . 


$$
53 / 54
$$

Table 9: Actual Thickness of the Stainless-Steel Cladding on the $B_{4} C$ Pellet as a Function of $V F_{t}$ and $V F_{b}$ ( $t$ given in inches) $)^{*}$.

\begin{tabular}{|c|c|c|c|c|c|c|c|c|}
\hline $\mathbf{V F}_{\mathbf{I}}$ & $V F_{b}=0.2$ & $V F_{b}=0.3$ & $V F_{b}=0.4$ & $V F_{b}=0.5$ & $V F_{b}=0.6$ & $V F_{b}=0.7$ & $V F_{b}=0.8$ & $V F_{b}=0.9$ \\
\hline 0.20 & 0.04825 & 0.03767 & 0.02925 & 0.02214 & {$[0.01592]$} & 0.01036 & 0.00531 & 0.00067 \\
\hline 22 & 0.04777 & 0.03719 & 0.02877 & 0.02166 & 0.01544 & 0.00988 & 0.00483 & 0.00018 \\
\hline 0.24 & 0.04726 & $0.03 \times 68$ & 0.02826 & 0.02114 & 0.01493 & 0.00937 & 0.00432 & \\
\hline 0.26 & 0.04671 & 0.03613 & 0.02771 & 0.02060 & 0.01438 & 0.00882 & 0.00377 & -0.00088 \\
\hline 0.28 & 0.04613 & 0.03555 & 0.02713 & {$[0.02002]$} & 0.01380 & 0.00824 & 0.00319 & -0.00146 \\
\hline 0.30 & 0.04551 & 0.03493 & 0.02651 & 0.01939 & 0.01318 & 0.00762 & 0.00257 & -0.00208 \\
\hline 0.32 & 0.04484 & 0.03426 & 0.02584 & 0.01873 & 0.01251 & 0.00695 & 0.00190 & -0.00274 \\
\hline 0.34 & 0.04413 & & 0.025 & 1802 & 0.01180 & 0.00624 & 0.00119 & -0.00346 \\
\hline .36 & 0.04336 & 78 & 0.02436 & $|0.01725|$ & 0.01103 & 0.00547 & 0.00042 & -0.00422 \\
\hline 0.38 & 0.04253 & & 0.02353 & & 0.01020 & 0.00464 & & -0.00505 \\
\hline 0.40 & 0.04164 & & 0.02264 & 552 & 0.00931 & 0.00375 & -0.00130 & -0.00595 \\
\hline 0.42 & 0.04066 & 0.03008 & 0.02166 & 0.01455 & 0.00833 & $0.0027 ?$ & -0.00228 & -0.00692 \\
\hline 0.44 & 0.03960 & 0.02902 & {$[0.02060]$} & 0.01 & 0.00727 & 0.00171 & -0.00334 & -0.00799 \\
\hline 0.46 & 0.0 & 0.02 & 0.01943 & 232 & 0.00610 & & & 00915 \\
\hline 0.48 & & & & & 0.00482 & & 579 & 1043 \\
\hline 0.50 & & & & 0.00962 & 0.00340 & -0.00216 & 0721 & -0.01 \\
\hline 0.52 & & & 0.01515 & 0.00804 & 0.00182 & -0.00374 & -0.00879 & -0.01343 \\
\hline 0.54 & 0.03238 & 0.02180 & 0.01338 & 0.00627 & 0.00005 & -0.00551 & -0.01056 & -0.01521 \\
\hline 0.56 & 0.03038 & $0.01980]$ & 0.01138 & 0.00426 & $-\overline{0.00} \overline{19} \overline{5}$ & -0.00751 & -0.01256 & -0.01721 \\
\hline 0.58 & & 0.01751 & 0.00909 & & -0.00424 & -0.00980 & -0.01485 & -0.01950 \\
\hline 0.60 & 0.02545 & 0.01487 & 0.00645 & & -0.00688 & -0.01244 & -0.01749 & -0.02214 \\
\hline
\end{tabular}

Note:

1. $V F_{f}=\operatorname{Vol}\left(\mathrm{MO}_{2}\right) /\left[\operatorname{Vol}\left(\mathrm{MO}_{2}\right)+\operatorname{Vol}\left(\mathrm{B}_{4} \mathrm{C}\right)+\operatorname{Vol}(\mathrm{SS})\right]$

2. $\mathrm{VF}_{\mathrm{b}}=\operatorname{Vol}\left(\mathrm{B}_{4} \mathrm{C}\right) /\left[\operatorname{Vol}\left(\mathrm{B}_{4} \mathrm{C}\right)+\operatorname{Vol}(\mathrm{SS})\right]$

3. The thickness ( $t$ ), given in inches, does not include the steel associated with the spent fuel cladding hulls.

4. Those cases where $t$ is negative shou $I$ be disregarded as physically impossible.

5. Those cases below the solid stepped line should be disregarded as supercritical or very close to it $\left(k_{\infty}>0.95\right)$.

6. Brackets denote those cases where the actual $\mathrm{B}_{4} \mathrm{C}$ pellet cladding is 15-20-mils thick. 


\section{APPENDIX E}

\section{AUTOMATED PROCEDURE USED FOR GENERATING THE ACTUAL CSAS2 INPUT FOR THE CALCULATIONS DESCRIDED IN SECTIONS VI.C}

Because of resonance-self-shielding efferts in the fuel, and spatial-self-shielding effects in the

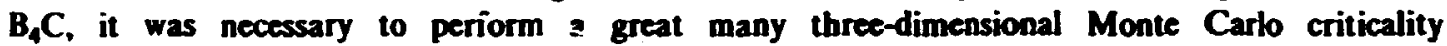
calculations with fuel lumps of some specified size and steel-clad $\mathrm{B}_{4} \mathrm{C}$ pellets of some specified size (0.25-inch outside diameter) both dispersed in a uniformly random fasnion in water. More specifically, it was necessary to determine the reactivity of the system at all $\mathrm{H} / \mathrm{Pu}$ ratios as the fuel lumps slow!y dissolve. To that end, four series of three-dimensional Monte Carlo calculations were performed:

Case (z): $D_{t}=$ diameter of frel lump $=1.00 \mathrm{~cm}$
Case $(y): D_{t}=$ diameter of fuel lump $=0.67 \mathrm{~cm}$
Case $(x): D_{t}=$ diameter of fuel lump $=0.33 \mathrm{~cm}$
Case $(w): D_{r}=$ diameter of fuel lump $=0.10 \mathrm{~cm}$

In each case, $V F_{f}$ and $V F_{b}$ were held constant (at 0.34 and 0.50 , respectively) while the $H / P u$ ratio was varied from 0 to 10,000 . To uniquely identify the output, each series of calculations was assigned a special three-character ID:

\begin{tabular}{|c||c|c|c|c|}
\hline Series & $(\mathbf{w})$ & $(\mathbf{x})$ & $(\mathbf{y})$ & $(\mathbf{z})$ \\
\hline ID & $\mathbf{W W W}$ & $\mathbf{X X X}$ & $\mathbf{Y Y Y}$ & $\mathbf{Z Z Z}$ \\
\hline
\end{tabular}

Each individual calculati- in a series was further identified by an integer $I(1 \leqslant I \leqslant 40)$ which denotes one of the $i 1, "$. number ratios, HPU(I), in the PDP-10 FORTRAN deck listed below. Indeed, the entirc PEP'10 'MIC' file (KEFF3D.MIC) used to generate the actual CSAS2 input for the calculations sited in Section VI.C is shown below. To perform all 40 calculations in the series corresponding to case $(x)$, one would only need to enter:

$$
\text { .DO KEFF3D.MIC 0.33,XXX,1,40,1 , }
$$

while to perform only every alternate one for case $(y)$, one would only need to enter

$$
\text { .DO KEFF3D.MIC 0.67,YYY,2,40,2 . }
$$

Here, the sirst parameter is the assumed diameter of the fuel lump in centimeters; the second parameter is the alphanumeric series ID; and the third, fourth, and fifth parameters $(\mathrm{N} 1, \mathrm{~N} 2, \mathrm{~N} 3)$ designate which elements of the series (HPU(I),I $=N$ !, N2,N3) are to be submitted. Note that all of the output from each CSAS2 calculation is saved on microfiche, and that some of the key results (such as $k_{e f r}$ and some of the convergence parameters) are also saved on punched cards. Also note that the various changes to the KENO-IV tracking routines (that were necessary to model a uniformly sandom array of mixed box types) are listed below. Complete listings of these routines, including the necessary modifications, will be saved on the same microfiche as the CSAS2/KENO-IV output. 


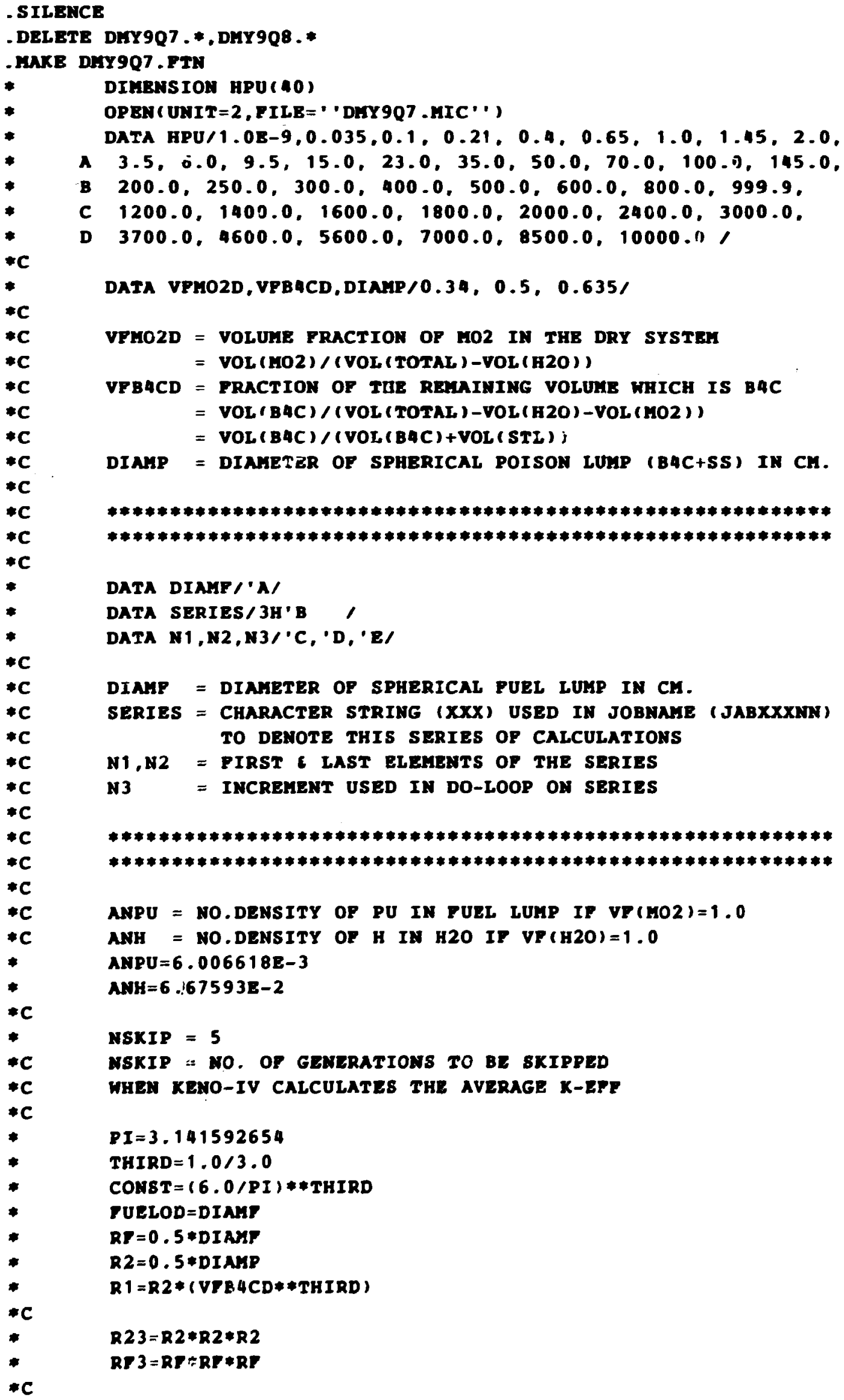




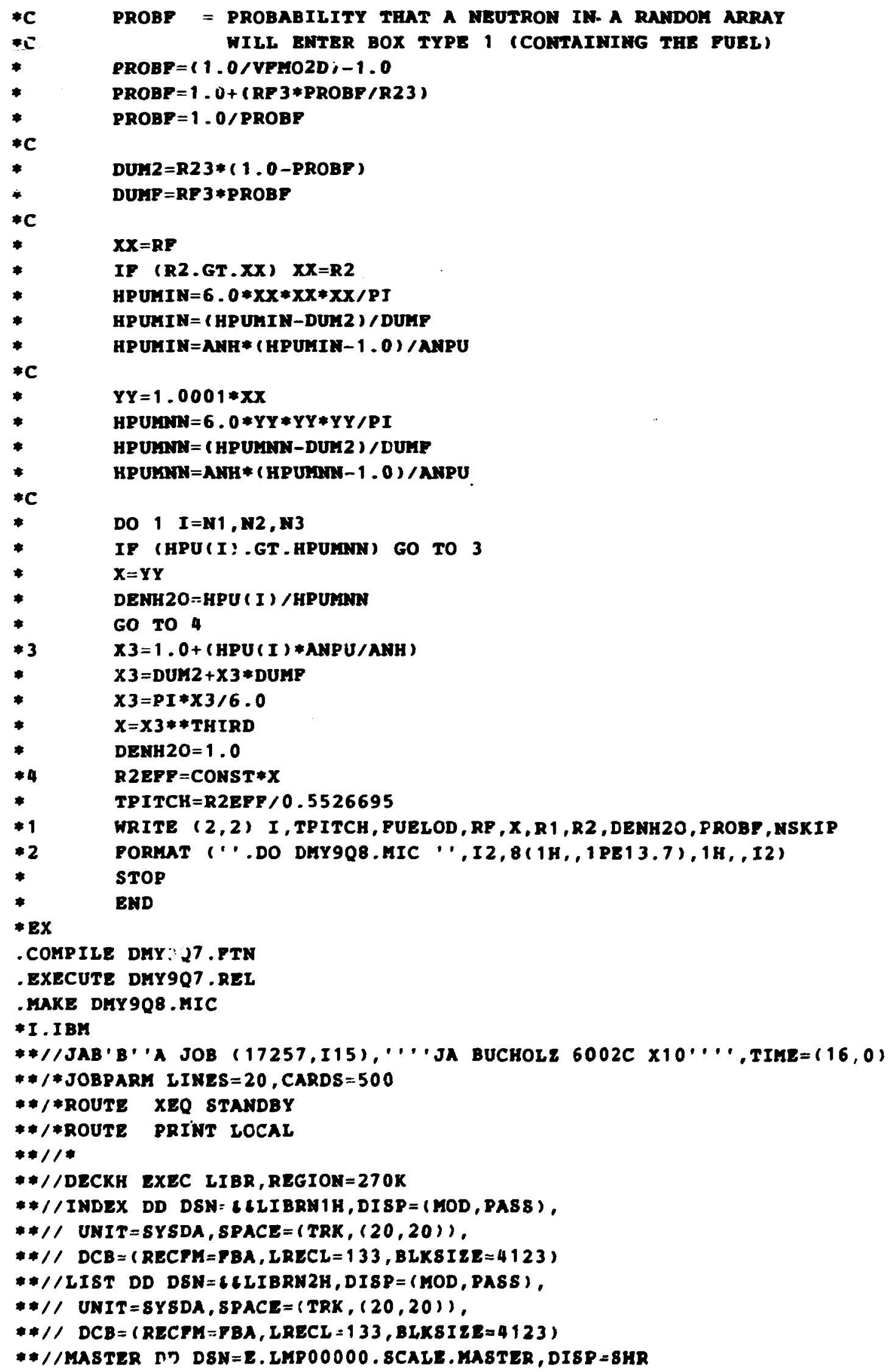




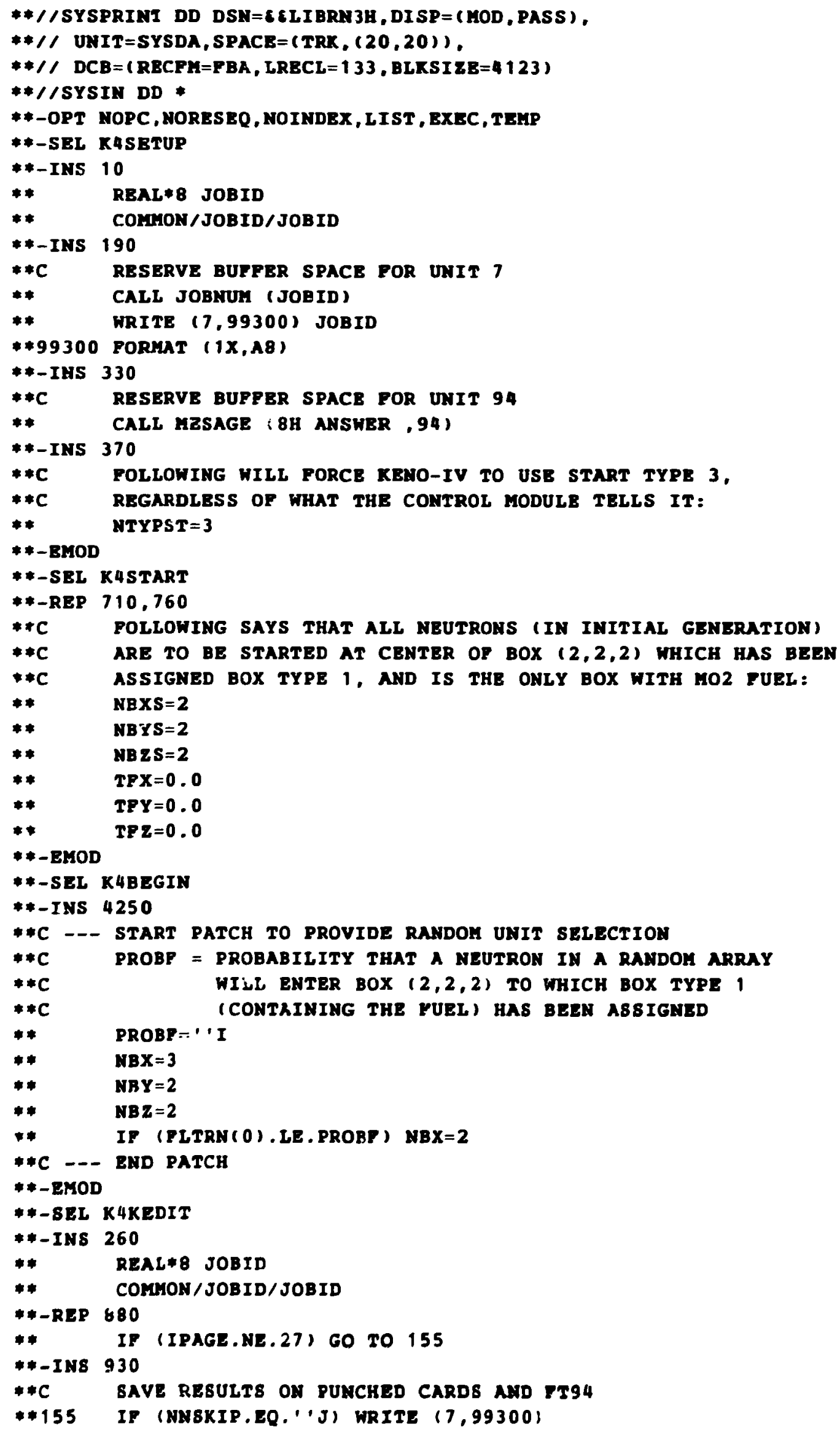




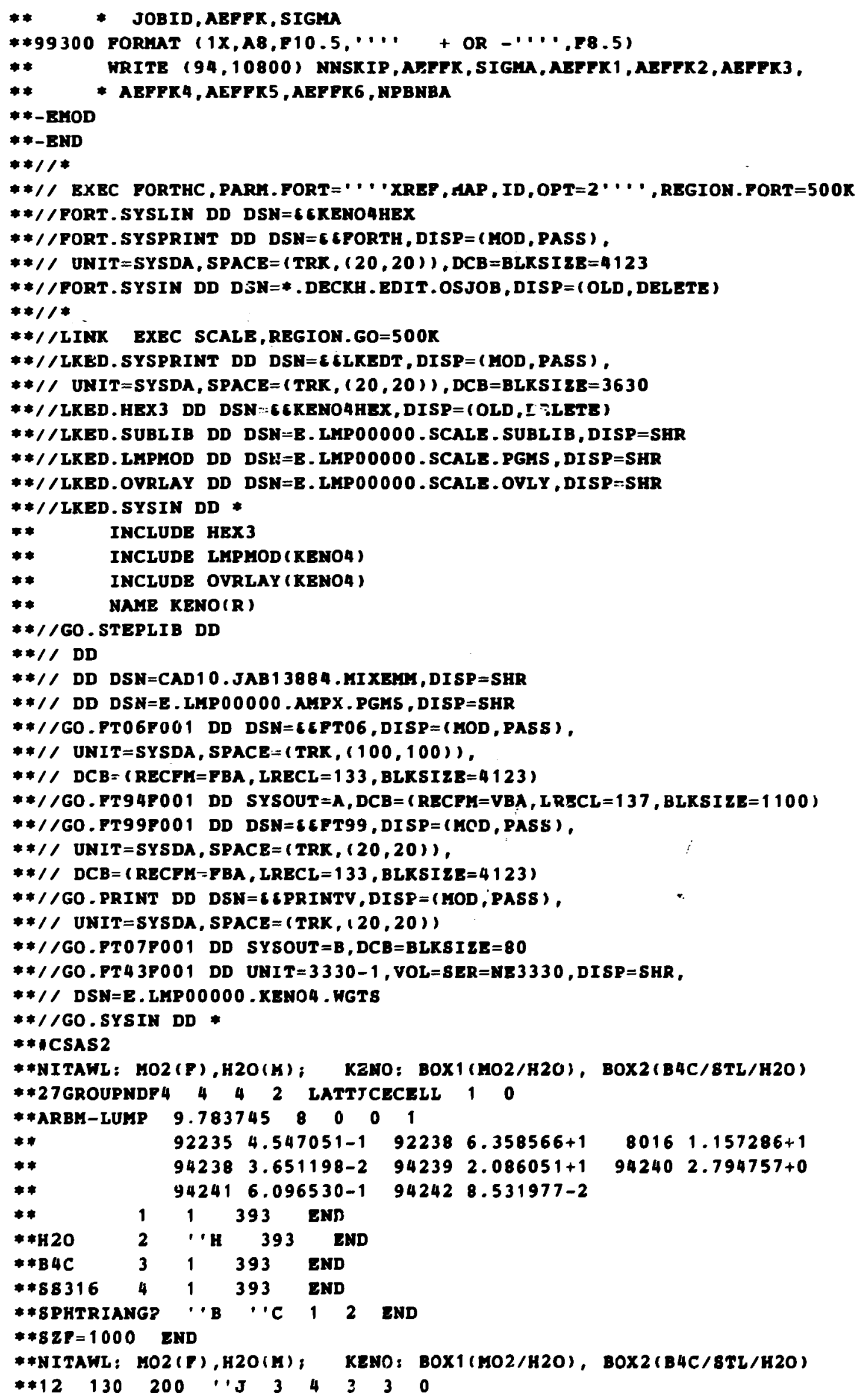




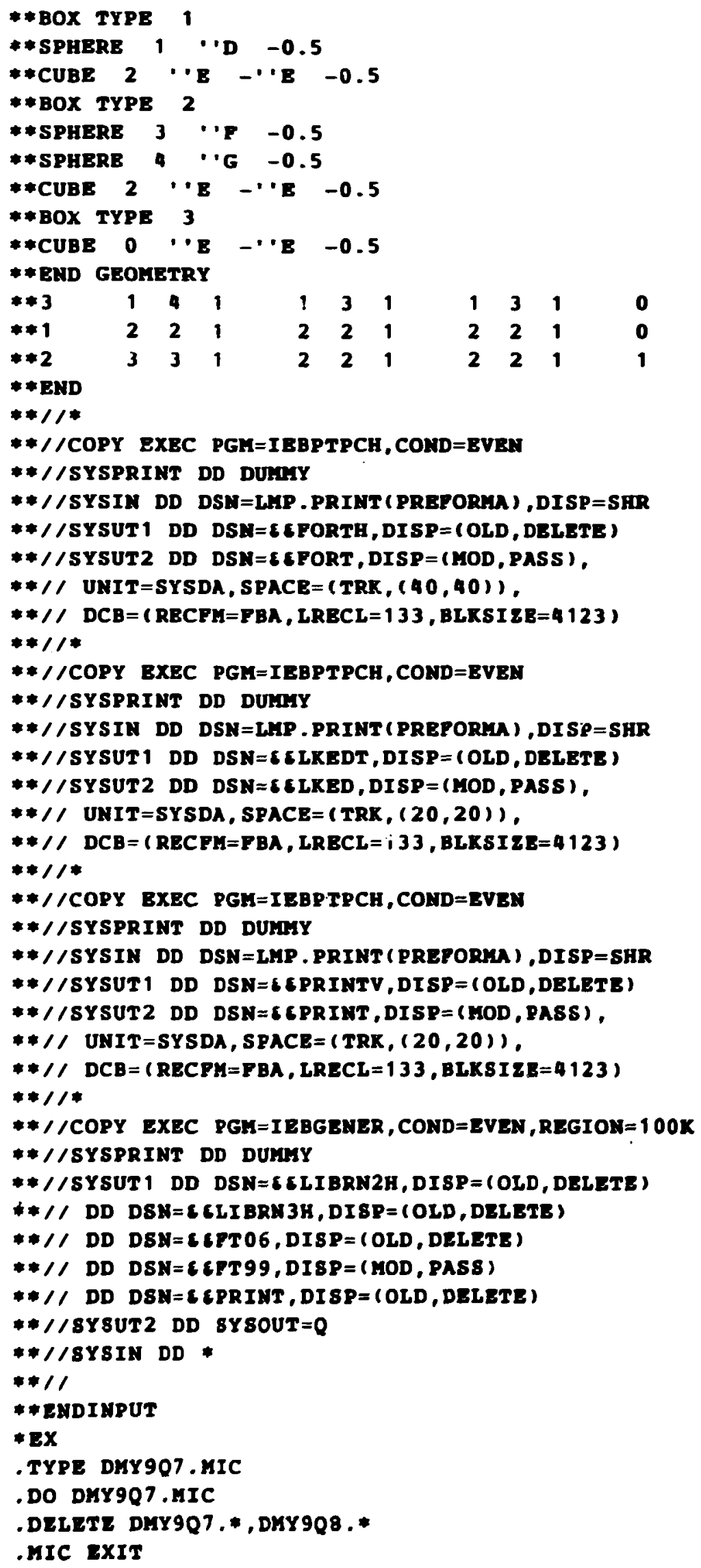


INTERNAL DISTRIBUTION

1. J. D. Birdwell, Jr.

2. B. F. Botteafield

3-5. W. D. Barch

6-10. J. A. Bactwolz

11. H. P. Carter/G. E. Whitesides/ CS X-10 Library

12 D. J. Crouse

13. F. C. Davis

14. R. V. Eberle

15. R. D. Ehrlich

16. M. J. Feldanan

17. J. O. Hylton

18. R. W. Glass

19. W. S. Groenier

20. W. R. Hamel

21. D. C. Hampson

22. A. L. Harkey

23. J. N. Herndon

24. D. T. Ingersoll

25. R. A. Jacobus

26. B. E. Lewis

27. S. A. Meacham

28. D. R. Moser

29. L. M. Petrie

30. R. L. Philippone, DOE

31-35. R. T. Primm, III

36. D. P. Reid

37. J. A. Renier
38. J. C. Ryman
39. S. P. Singh
40. G. E. Swith
41. J. G. Stradley
42. J. E Straia
43. J. S. Tang
4. J. T. Thomes
45. J. W. Wachter
46. F. E. Weber
47. C. C. Webster
48. J. R. Weir
49-53. R. M. Westiall
54. J. E Wortina
55. O. O. Yartro
56. H. R. Yoot
57. Masson Benedict
(Comseltant)
58. A. Schneider
(Consultant)
59-63. Engiveering Physics
Information Center
64. K-25 CS Library
65. Ceatral Research Library
66. Y-12 Document Refereace
Section
67-68. Laboratory Records
69. Laboratory Records - RC
70. ORNL Pateat Section

\section{EXTERNAL DISTRIBUTION}

71. Chief, Mathematics and Geoscieace Branch, Department of Energy, Washington, DC 20545.

72. Ofrice of Asst. Manager for Energy Rese arch and Development, Department of Energy/ORO, Oak Ridge, TN 37830.

73-74. K. O. Laughon, Jr., Director, OMee of Spent Fuet Management and Reprocessing Systems, U.S. Departmeat of Energy, Washingtom, DC 20545

75. F. P. Baranowski, 1110 Dapple Grey Court, Great Falls, VA 22066

76. S. J. Beard, Vice President, Engineering and Technology, Exxon Nuclear Company, Ioc., 600 108th Arenue, N.E., C-00777, Bellerve, WA 98009

77. R. Little, Princeton Plasma Physics Laboratory, James Forrestal Campus, P.O. Box 451, Priacetom, NJ 08544

78. J. L. McElroy, Pacific Northwest Laboratories, P.O. Box 999, Richland, WA 99352

79. M. J. Otanian, Ascociate Deas for Research, Colkge of Engineering, 300 Weil Hall, University of Florida, Gaineaville, FL 32511 
80. J. F. Proctor, Seaier Techaical Specialist, Petrochenicals Department,

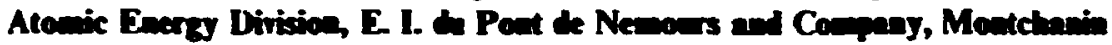

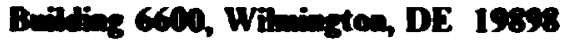

81. J. N. Rogers, Division 8324, Santia Lalooratories, Livernore, CA 94550. 82-188. Given Distrilution as shown in TID-4500 (Rer. 72, 9/83) wader UC-86. 